June 2000 - NREL/TP-500-27514

\title{
Modeling Utility-Scale Wind Power Plants Part 1: Economics
}

Michael R. Milligan

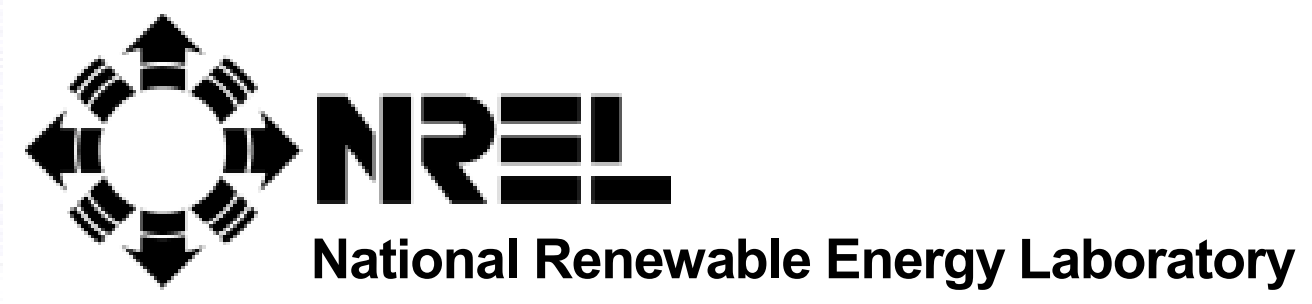

1617 Cole Boulevard

Golden, Colorado 80401-3393

NREL is a U.S. Department of Energy Laboratory

Operated by Midwest Research Institute $\bullet$ Battelle $\bullet$ Bechtel

Contract No. DE-AC36-99-G010337 


\title{
Modeling Utility-Scale Wind Power Plants Part 1: Economics
}

\author{
Michael R. Milligan
}

Prepared under Task No. WE90.3210

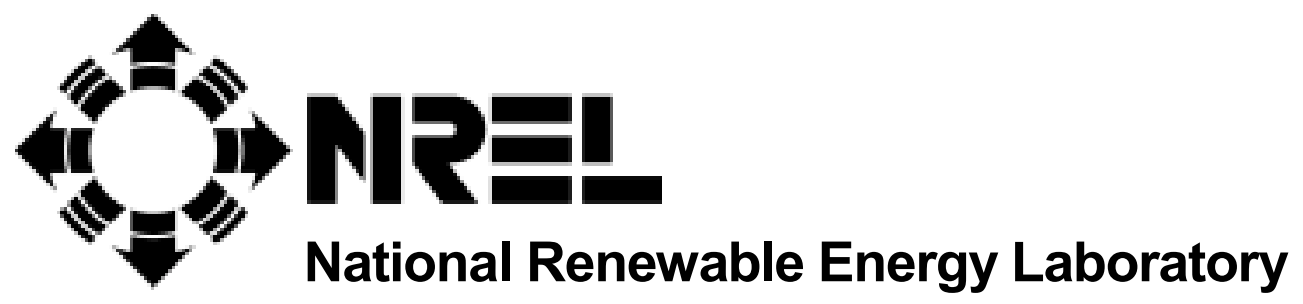

1617 Cole Boulevard

Golden, Colorado 80401-3393

NREL is a U.S. Department of Energy Laboratory

Operated by Midwest Research Institute • Battelle • Bechtel

Contract No. DE-AC36-99-G010337 


\section{NOTICE}

This report was prepared as an account of work sponsored by an agency of the United States government. Neither the United States government nor any agency thereof, nor any of their employees, makes any warranty, express or implied, or assumes any legal liability or responsibility for the accuracy, completeness, or usefulness of any information, apparatus, product, or process disclosed, or represents that its use would not infringe privately owned rights. Reference herein to any specific commercial product, process, or service by trade name, trademark, manufacturer, or otherwise does not necessarily constitute or imply its endorsement, recommendation, or favoring by the United States government or any agency thereof. The views and opinions of authors expressed herein do not necessarily state or reflect those of the United States government or any agency thereof.

Available electronically at http://www.doe.gov/bridge

Available for a processing fee to U.S. Department of Energy

and its contractors, in paper, from:

U.S. Department of Energy

Office of Scientific and Technical Information

P.O. Box 62

Oak Ridge, TN 37831-0062

phone: 865.576.8401

fax: 865.576.5728

email: reports@adonis.osti.gov

Available for sale to the public, in paper, from:

U.S. Department of Commerce

National Technical Information Service

5285 Port Royal Road

Springfield, VA 22161

phone: 800.553.6847

fax: 703.605.6900

email: orders@ntis.fedworld.gov

online ordering: http://www.ntis.gov/ordering.htm

Printed on paper containing at least $50 \%$ wastepaper, including $20 \%$ postconsumer waste 


\section{Table of Contents}

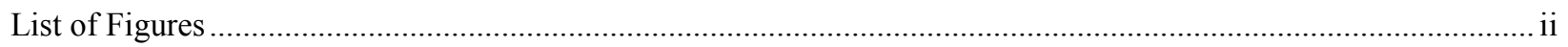

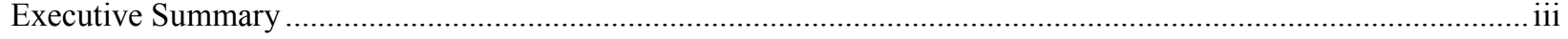

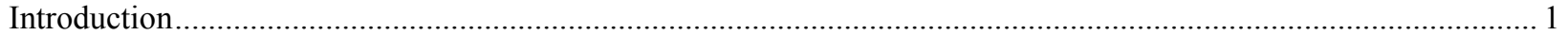

Production-Cost Modeling: Load Duration Curve and Chronological Models....................................................... 3

Load-Duration Curve Modeling and Case Studies Using Elfin ................................................................ 4

Load-Modification Modeling Method …........................................................................................... 5

Case Studies Using the Load-Modification Modeling Method With Elfin ................................................... 6

Modeling Wind Power Plants as a Supply-Side Resource with Elfin .................................................... 8

Probabilistic Time-varying Artificial FORs with Elfin: Modeling Results.............................................. 10

Chronological Production Cost Models: P+....................................................................................... 11

LDC and Chronological Model Comparisons: Commitment and Economic Dispatch...................................... 12

Case Studies of Wind Power Plants Comparing LDC and Chronological Models ......................................... 14

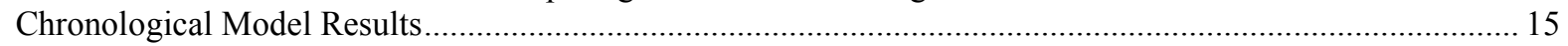

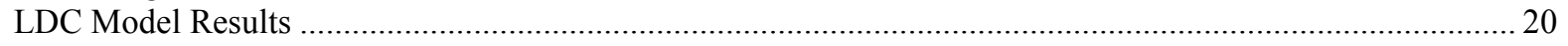

Comparison of Model Results: Chronological vs. LDC …................................................................... 22

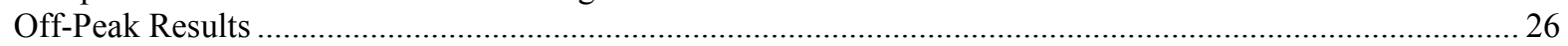

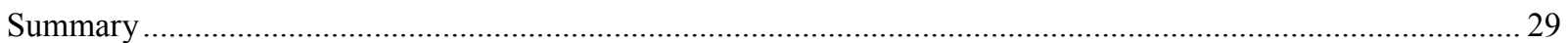

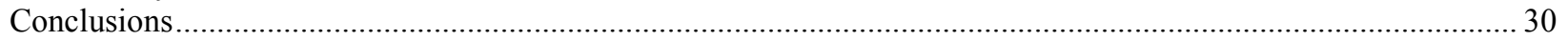

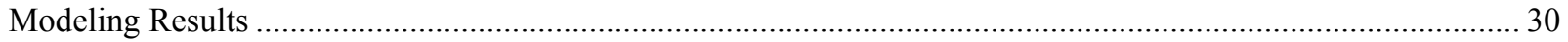

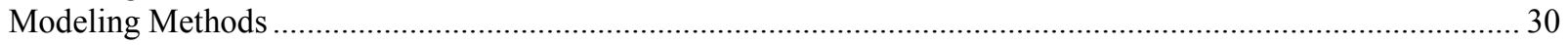

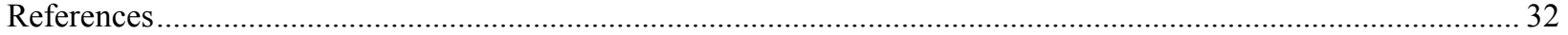




\section{List of Figures}

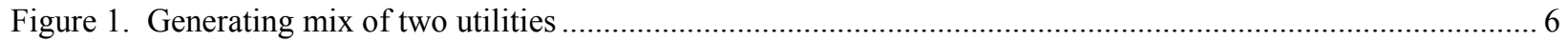

Figure 2. Simulation results for all combinations of utilities, wind resources, and wind turbines using

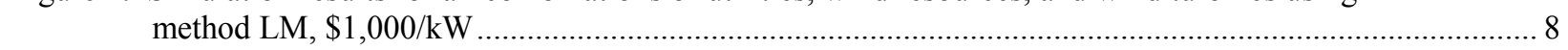

Figure 3. Site WC -Weibull surface, typical day, January .............................................................................. 9

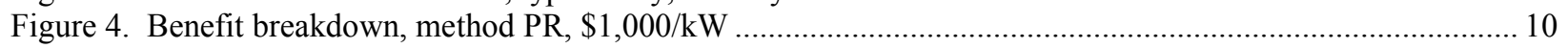

Figure 5. Cumulative wind power difference distribution, site HP, July ............................................................... 11

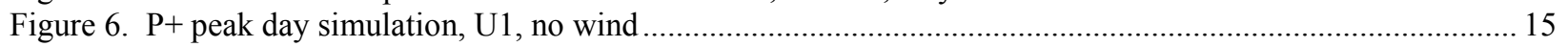

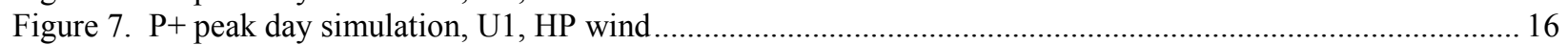

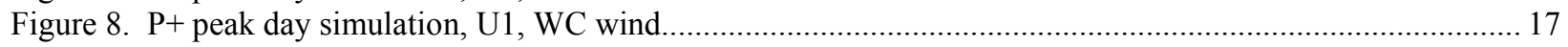

Figure 9. P+ average day in peak week, U1, HP wind .................................................................................. 18

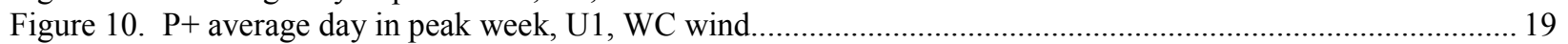

Figure 11. $\mathrm{P}+$ comparison of wind and no-wind cases, change in energy generation by unit type........................... 19

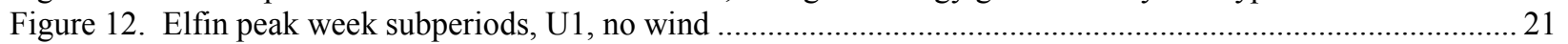

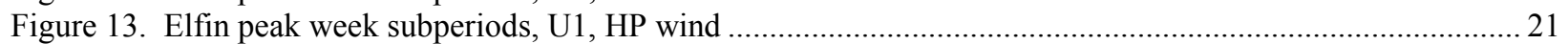

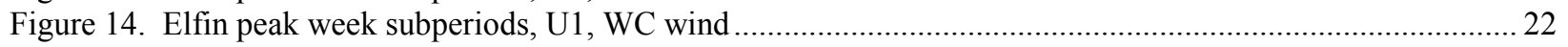

Figure 15. Percent production cost reduction from base case, U1, HP wind ........................................................ 22

Figure 16. Percent production cost reduction from base case, U1, WC wind ........................................................ 23

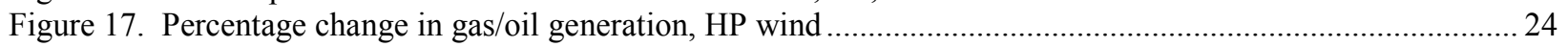

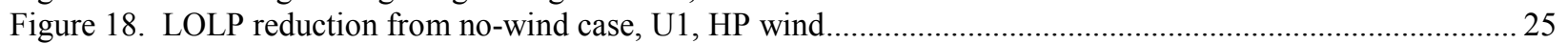

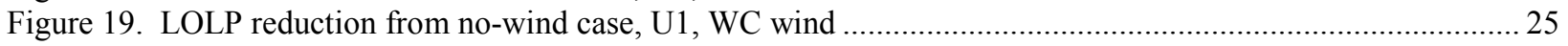

Figure 20. Production cost reduction, U1, HP wind, low-load case.................................................................. 27

Figure 21. Production cost reduction, U1, WC wind, low-load case ...................................................................28

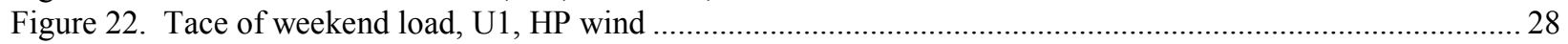




\section{Executive Summary}

As the worldwide use of wind turbine generators continues to increase in utility-scale applications, it will become increasingly important to assess the economic and reliability impact of these intermittent resources. Although the utility industry in the United States appears to be moving towards a restructured environment, basic economic and reliability issues will continue to be relevant to companies involved with electricity generation. This paper is the first of two that address modeling approaches and results obtained in several case studies and research projects at the National Renewable Energy Laboratory (NREL). This first paper addresses the basic economic issues associated with electricity production from several generators that include large-scale wind power plants. An important part of this discussion is the role of unit commitment and economic dispatch in production-cost models. This paper includes overviews and comparisons of the prevalent production-cost modeling methods, including several case studies applied to a variety of electric utilities. The second paper discusses various methods of assessing capacity credit and results from several reliability-based studies performed at NREL. 


\section{Introduction}

Renewable energy technology has matured significantly over the past several years. In particular, wind turbines are becoming much more reliable and technically sophisticated. New machines feature more advanced controls, and the industry is beginning to develop machines with variable-speed generators. Meanwhile, electricity markets are undergoing change in many parts of the United States and throughout the world. New markets for "green power" are emerging, and while the ultimate outcome of these new market forces is unknown, it seems clear that renewable energy sources will play an important role in future electricity production.

The new restructured markets in the United States are not likely to be free of all regulation. For example, the new market in California provides for a renewable energy resource buy-down program to help attain emission and other environmental goals for the state. During transition periods to newly restructured markets, state and/or federal utility regulators will monitor the degree of market power and the overall reliability of electric service. Generating companies will hold a portfolio of generating units and will bid into various local and regional pools according to the generator characteristics, profit motives, and regulatory influences, if any.

A well-known uncertainty with the economics of electricity generation is the cost of externalities such as emissions. Various forms of emissions, whether chemical, particulate, or thermal, are not fully incorporated into the private cost function of the generating company. Although a market for emissions trading was developed in the United States to reduce the cost of sulfur dioxide emissions, private and social costs of power generation continue to diverge because of other emissions.

Electricity production-cost models have been used for many years to assist utility planners in assessing fuel costs and system reliability. The role and usage of such models will certainly change over the next several years, and under restructuring, there is a decoupling of cost and price. However, least-cost dispatch is still a requirement to firms that pursue profit-maximization goals. Therefore, applying these models to electric markets can still provide insight into electricity generation in new markets. The purpose of this paper is to summarize results from some of the work performed at the National Renewable Energy Laboratory over the past several years on topics ranging from estimates of capacity credit and economic benefits to the value of wind forecasting. We will examine the economics of wind power production, reliability, capacity credit results and issues, and examine the modeling of wind energy systems in production-cost models.

Given the uncertainty of how market participants will behave under restructuring, it is not obvious that traditional least-cost dispatch will occur in these markets. Although some analysts ${ }^{1}$ predict that generators will bid their marginal cost, the incentives to exercise market power and to recover generator start-up and other costs may drive generating companies to bid above marginal cost. Whether commitment and start-up comprise part of an ancillary services market or whether generators will be able to calculate bid prices that cover start-up costs is not clear. However, until these issues are resolved, it appears reasonable to perform analyses in the context of cost-minimization. As the restructuring process unfolds, it will be important to review this important issue.

Long-term entry into the generation market will be modeled differently than in the past, when productioncost models were run in "generation expansion" mode. Marnay ${ }^{2}$ illustrates the use of the Elfin production cost model to estimate the supply curve of wind power plants in the California power market. Although his model uses a newly developed profit-maximizing algorithm to simulate new entry into the power market, dispatch is based on the usual cost-minimization algorithm found in most production-cost models. 
Recent work that characterizes the emerging electricity markets, such as $\mathrm{Kahn}^{3}$, Surratt ${ }^{4}$, and Berry ${ }^{5}$ are all based on this assumption of cost-minimization.

It is hard to tell precisely what will survive in the new electricity market, but we believe that the core issues examined in this work will continue to be relevant, albeit to different players in the market. I use the term "utility" to mean something akin to "generating company." 


\section{Production-Cost Modeling: Load Duration Curve and Chronological Models}

The two predominate model styles are load-duration curve (LDC) models and chronological models. The primary advantage of the LDC model is its computational efficiency, which comes at a price of sacrificing chronological outputs and accuracy with respect to start-up and other costs associated with unit commitment. In testing we found that the economic benefits of a wind power plant were similar with both types of models. This discussion summarizes that in Milligan ${ }^{6}$ and Milligan and Miller. ${ }^{7}$ The LDC model we use is Elfin, developed by the Environmental Defense Fund. Our chronological model is $\mathrm{P}+$, which was derived from the PowerSym model developed at the Tennessee Valley Authority (TVA) and commercialized by the P Plus Corporation. More complete results can be found in the original papers.

Production-cost models serve an important need in the utility industry because they allow analysis of the complicated interactions between hourly electric loads and generators. Whether we are analyzing a monopolistic industry subject to regulation or a competitive industry (given fixed generating stock), the utility company will normally attempt to minimize production costs, subject to the operating constraints of the power plants. Ignoring these temporal interactions, the cost-minimization problem can be written as

$$
\min \sum_{i=0}^{m}\left(p_{i} r_{i}\right)
$$

subject to

$$
\mathrm{g}(\mathrm{y} 1, \mathrm{y} 2, \ldots, \mathrm{ym})=\mathrm{x}
$$

where $m$ is the number of power plants, $r_{i}$ is the cost of fuel for plant $i, p_{i}$ is the output of generator $i, x$ is the demand for energy, and $g\left(\right.$ describes the power production as a function of the input to each plant $y_{i}$ (see, for example, Silberberg ${ }^{8}$ ). This type of problem can generally be solved by Lagrangian, KuhnTucker, linear programming, or non-linear programming techniques, depending on the linearity of the constraint function $g()$ and the formulation of the problem. However, when we apply one of these costminimization strategies to power systems, we have a series of $N$ equation systems like those in equations (1) and (2), one for each hour of the year. Furthermore, inter-temporal constraints on power plant operations (many thermal power plants cannot normally be started and stopped from hour to hour) cause mathematical solutions to become unwieldy or impossible to solve. This is the reason that utilities have found production cost models increasingly useful as computing has become more powerful and power systems have become more complex. (Grubb ${ }^{9}$ provides an excellent discussion, analysis, and modeling results of wind power plants.)

An important by-product of these models typically includes a measure of system reliability. Because all power plants can malfunction, there is always a non-zero probability that the total power output of the combined power plants is insufficient to meet the customer load. This measure is called the loss-of-load probability (LOLP) and, in this context, does not measure the probability that the transmission or distribution systems might contribute to system failure. Using the LOLP, other related measures can be computed. Some of these include loss-of-load hours (LOLH), which is the number of hours per year that failure is expected to occur; and loss-of-load expectation (LOLE), which is frequently calculated in the number of days per year that failure is expected. All of these measures are capacity-based and do not 
account for energy loss that results from system failure. An energy-based reliability measure is normally expressed in gigawatt-hours (GWh) per year, and is referred to as expected energy not served (EENS), energy not served (ENS), or expected unserved energy (EUE).

\section{Load-Duration Curve Modeling and Case Studies Using Elfin}

When modeling wind power plants, it is important to retain as much chronological information as possible, so that we capture the proper time-scale relationship between customer load and wind power output. In this regard, LDC models can do surprisingly well. The Elfin model uses the LDC representation of loads, yet allows a full year of hourly load and wind power data. Although older versions of the model created a single representative week for each month, recent versions have the ability to model each of the 52 weeks in a year. This provides a more plausible representation of the wind power plant than using one typical week per month, which smooths the wind power fluctuations more than would be observed in practice.

LDC models build load duration curves by dividing the chronological loads into different time periods. Elfin, for example, divides the loads into weeks, and each week is divided into sub-periods. The subperiods can be specified by the user and are usually defined in accordance with the utility's definitions of peak, off-peak, super off-peak, etc. For each of these sub-periods, the model first constructs LDC, then performs the unit commitment and economic dispatch modules. Within each of these sub-periods, the model assumes that each supply-side resource provides a constant level of capacity (although this capacity level is subject to the forced outage and maintenance outage rates). Typically, time-varying supply-side generator schedules are averaged across the sub-period.

Elfin allows for a large number of generator types, including both supply-side and demand-side resources, both firm and nonfirm. There are several types of load modifiers, which can be applied as either demandside or supply-side resources depending on whether unit commitment and loss calculations are to include the resource. Historically, intermittent generators, such as wind, have been modeled in this way, because load modifiers are applied to the chronological loads prior to constructing the LDC. This provides the model with the highest possible resolution for wind power. However, applying the load-modification approach to wind generation implies that each calculated value of hourly wind power output is available with certainty. This means that, although there is some probability that wind power will be available at a reduced level, that probability is not taken into account when the overall system LOLE is calculated. Likewise, if the hourly generation of the wind plant is below maximum rated power, there is a probability that output will be higher than that value used by the model. The second paper discusses simulation methods that provide a way to analyze the probabilities of these variations.

Supply-side resources can be designated with either fixed or time-varying generation schedules. If a resource is not a load modifier, its capability is averaged for the time period, accounting for forced and planned (maintenance) outages, unless the plant is modeled with a series of forced outages rates, as described below. Generators can be subjected to certain constraints, most notably, energy constraints for months, seasons, or years. A plant can be designated as "must-run," which means that the plant runs irrespective of its cost, but is otherwise deployed in merit order. (Must-run constraints may still be important under restructuring, although the must-run requirements of a plant may be related to the various ancillary or local services it provides). Thermal plants can be modeled in up to nine blocks, each with its own heat rate and forced outage rate (FOR). The FOR is an estimate of the probability that the unit will be unable to provide the relevant capacity when needed. The block size in megawatts and the FORs can change on an hourly basis (and are subsequently combined into the sub-period). Elfin can optimize maintenance scheduling so that sufficient resources are on-line to meet the system peak. Elfin allows for consideration of externalities and maintenance as part of cost if desired, and contains an option to perform the dispatch algorithm that is subject to minimizing an objective emission function. 
The user can set the commitment target to be either some combination of a percentage of system load or an adder to the period peak load. This target contains the utility native load, losses, and any operating reserve requirement. Commitment refers to the level of spinning and quick-start capacity that is available. Slow-start units, once committed, can be dispatched to meet load. The user also can set the spinning target, which is the constraint observed for the reserve requirement during the period. The spinning target can only be met with plants that are on-line and synchronized; whereas, the commitment target can be met with off-line quick-start units in addition to plants that are on-line.

Elfin calculates LOLP using a 201-point piecewise linear approximation to the LDC. LOLP can be calculated for any time period or for the entire year. The model provides an operating LOLP; off-line, uncommitted units are not considered in the LOLP calculations. Elfin has an option that allows the user to calculate hourly LOLP using all installed capacity with various options for including hydro, pumped storage, and other dispatchable reserves. These options are useful for performing reliability studies.

\section{Load-Modification Modeling Method}

One of the most common methods for modeling wind power plants is the "load-modification" method. As its name suggests, hourly wind power output is subtracted from the hourly loads prior to performing the commitment and dispatch routines. There is a certain appeal to this process. The marginal cost of wind power is normally near zero, except for operational and maintenance (O\&M) costs that are typically less than $\$ 0.01 / \mathrm{kWh}$. Conventional thermal power generation typically costs at least $\$ 0.02 / \mathrm{kWh}$ and is sometimes much greater. The ranking of generators by cost causes the wind plant to be ranked as the least expensive resource, and in accordance with cost-minimization principles, would be "scheduled" prior to committing other units. After this inexpensive resource is used, the conventional hydro-thermal generators are committed and dispatched in merit order. The load-modification method simulates this process on an hour-by-hour basis before turning to the least-cost dispatch of the LDC. Therefore it takes into account the hourly variation in wind power output and "dispatches" the wind resource first. In this sense, wind plants are baseload resources for which the value equals the cost of the displaced marginal generating unit.

With most LDC models, such as Elfin, this load-modification method occurs internally prior to constructing the load-duration curve. Therefore, hydro-thermal dispatch is performed to the load net-ofwind power. No recognition is given to the stochastic nature of the wind resource during the reliability calculation. Also, the probabilistic assessment of the expected wind output equals the output for the hour in question. This implies that the system reliability calculation does not include a probabilistic assessment of attaining a level of wind power that differs from the fixed amount during the hour. This contrasts with the recognition that conventional generators may not be available to meet load, given an estimated probability that is typically based on historical data and incorporated into the system reliability assessment.

Another interesting implication appears as a result of the load-modification method. With the Elfin model, the analyst has a choice of whether to specify the wind power plant as a firm or non-firm resource. Firm resources are those whose output can be expected with very high probability. This probability level is sometimes debated. It seems clear, however, that no power plant is ever perfectly firm, because competent modelers provide estimates of forced outage rates for all resource types. We can obtain some insight on the implications by examining the extreme cases. If we were to specify that the wind power plant is non-firm, then the model does not count any portion of the wind power towards the spinning reserve or commitment target. In this case, the modeler is in effect telling the model to add spinning reserves to cover the wind plant. Conversely, if we specify the plant as firm, then the entire wind plant output gets counted towards spinning reserve and the commitment target. Although the analyst can 
(sometimes with significant effort) choose a compromise value for the proportion of wind considered firm/non-firm, it is important to realize that, under these conditions, the model is incapable of telling us what the operational capacity credit of the wind plant might be. (Capacity credit will be discussed in detail in Part 2.)

We used this feature of the model to simulate the effect of various wind-speed/wind-power forecast accuracies, discussed in Part 2 of this paper. As will be seen, the usual method of specifying wind as an hourly-varying firm load-modifier implies perfect information about tomorrow's hourly wind power. This may not be a problem, because the load forecast is also assumed to be known with certainty by these models. Although there are ways of accommodating these objections, the analyst must perform significant processing externally to the model to properly address these concerns. One way of handling the omission of the wind plant from the reliability calculation is with the sequential Monte Carlo method, which is addressed in Part 2.

\section{Case Studies Using the Load-Modification Modeling Method With Elfin}

Milligan and Miller ${ }^{10}$ modeled two large utilities (hereafter referred to as U1 and U2) and explored the economic impact of a $125 \mathrm{MW}$ wind power plant on each system. The study looked at the impacts of power plants consisting of different wind turbines providing the same total rated capacity, and the influence of specific wind sites on economic value. Costs for the wind turbine installations were varied from $800 \$ / \mathrm{kW}$ up to $\$ 1,200 / \mathrm{kW}$, installed cost per rated capacity. Various production-cost model runs were carried out using Elfin with Bonus $300-\mathrm{kW}$ turbines and U.S. Windpower $360-\mathrm{kW}$ MVS-33 turbines.

The utilities' resource mix can be seen in Figure 1. Both utilities purchase approximately of $40 \%-45 \%$ of capacity, designated as "Prch" in the graph. Each has a very small percentage of combustion turbine (CT) capacity, near $30 \%$ oil and gas, and near $9 \%$ nuclear. Almost $16 \%$ of utility U1's capacity is supplied by hydro, whereas $\mathrm{U} 2$ has only about $4 \%$ hydro.
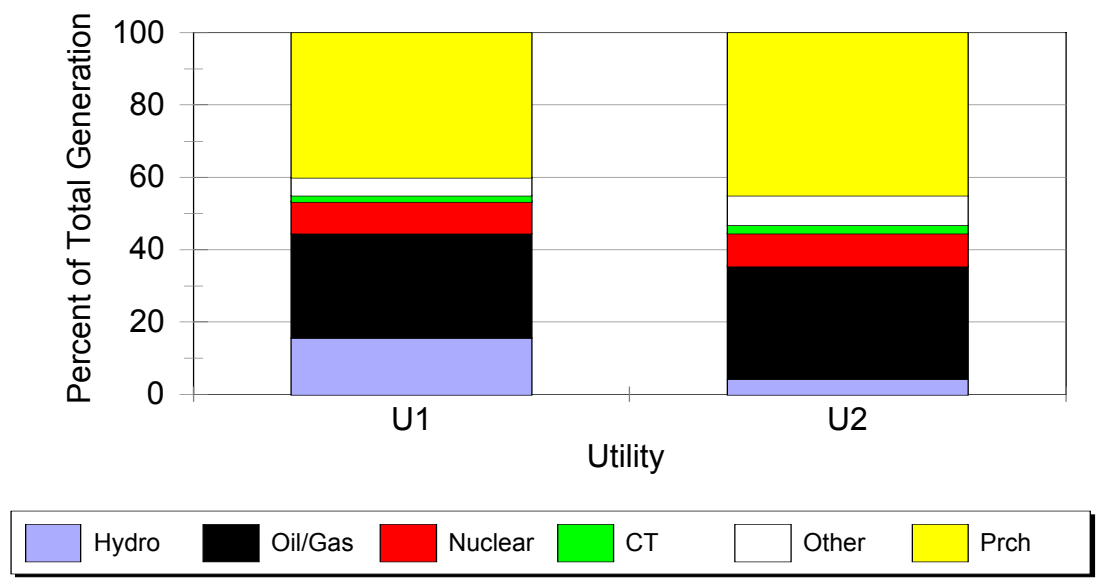

Figure 1. Generating mix of two utilities

All possible combinations of utility, wind turbine, and wind site were run through the model. Several aspects of the value of wind power were measured. The first is the value of fuel displaced. Although some analysts believe that wind power will replace energy from baseload units, this is clearly not the case. Displaced energy comes from the generating units that are on the margin - those units which, in the absence of wind power, were the last to be dispatched. 
The second component of wind-generating value that was measured is the capacity credit, which was measured in dollars. There are several ways of accounting for capacity credit, and further discussion appears in the second part of this paper. The method used in the simulations is called the "shortage" method, as adopted by the California Energy Commission, and documented in the Elfin Algorithms Guide. $^{11}$ The shortage method takes the capacity of the wind plant that is on-line during the annual system peak hour and uses that as the capacity. The dollar value of this capacity is based on the cost of a proxy unit, which is the generating technology that would most likely be adopted to eliminate the capacity shortage on peak. This would normally consist of one or more combustion turbines with a low capacity cost to fuel-cost ratio, providing a reasonable estimate of the value of capacity. The capacity value is simply the cost per installed MW of the combustion turbine multiplied by the shortage capacity.

The third portion of the value attributed to wind power plants is the value of reduced emissions. Although there is generally widespread agreement that emissions are negative byproducts of various types of generating technology, the specific cost imposed on society for each ton of emission is subject to debate. Development and justification of such emission penalties are well beyond the scope of this paper. The simulations under discussion used the following emission penalties, expressed in dollars per ton: $\mathrm{SO}_{\mathrm{x}}=\$ 8,719, \mathrm{NO}_{\mathrm{x}}=\$ 10,795$, particulates $=\$ 5,605$, reactive gases $=\$ 10,588, \mathrm{CO}=\$ 2,284$, and $\mathrm{CO}_{2}=\$ 29$.

The wind-speed data for these hypothetical wind plants are based on actual wind data collected as part of the Department of Energy Candidate Site Program. ${ }^{12}$ The first wind site is a high plains location (referred to as HP hereafter), and the second is located on a west coast mountain pass (WC). Power output was calculated on an hourly basis, accounting for electrical losses, wake effects, and mechanical availability.

Figure 2 shows the simulation results for all combinations of $U 1$ and $U 2$, the two wind turbines, and the $\mathrm{HP}$ and $\mathrm{WC}$ wind sites. In some cases, the combination of energy and capacity values are enough to offset the cost of the wind power plant. In other cases, the plant will not break even unless emissions are valued in the simulation. All of the simulations at the HP site provide benefits in excess of costs. 


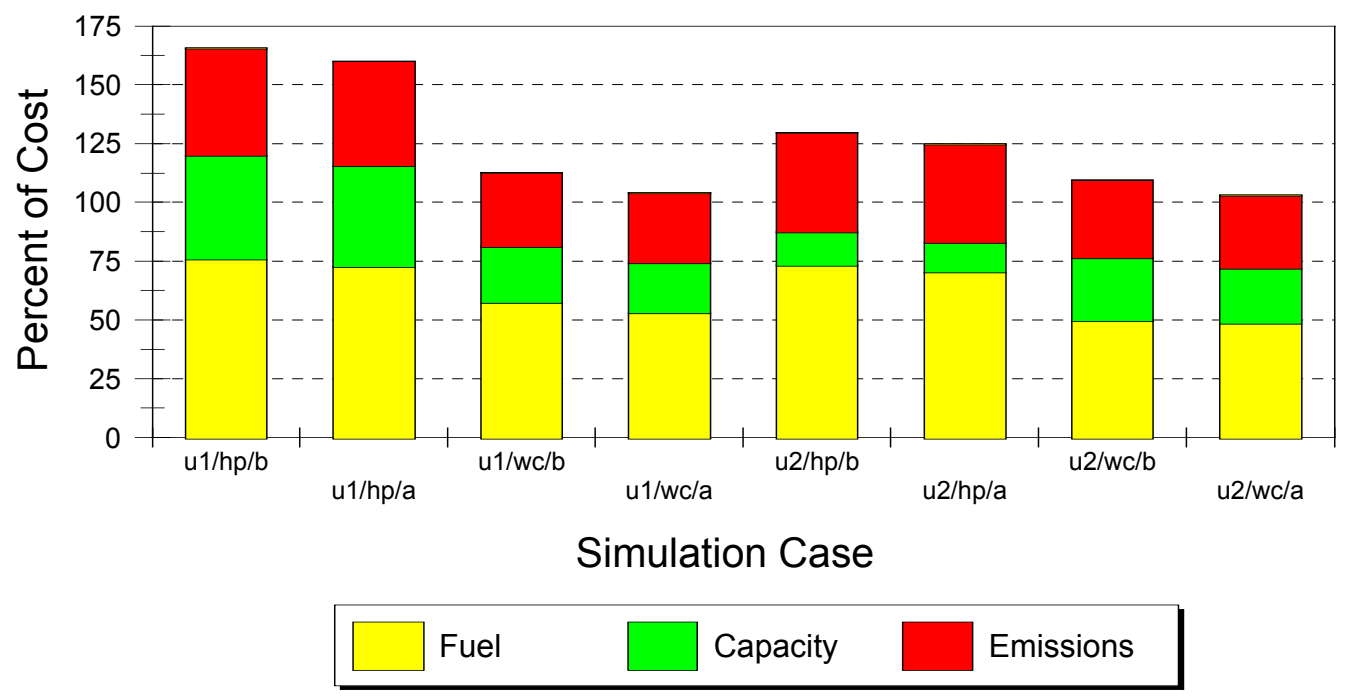

Figure 2. Simulation results for all combinations of utilities, wind resources, and wind turbines using method LM, $\$ 1,000 / \mathrm{kW}$

The differences in results for the two utilities are striking. The fuel displacement value appears to be similar, given comparable wind sites and turbines. However, the capacity value is quite different for each utility. This indicates that the capacity value depends heavily on the correlation of the utility's peak load and generator characteristics with the wind resource. This also reveals a weakness of the shortage method for calculating capacity value of wind plants. Because the shortage value is based only on the annual peak hour, relatively small changes in load patterns or in the timing of the wind energy can have large effects on the capacity value. My observation is that capacity credit measures should be based on broader statistics that offer more robustness than that obtained by the shortage method. The second paper in this series will explore other measures of capacity credit.

\section{Modeling Wind Power Plants as a Supply-Side Resource with Elfin}

A second broad method of modeling treats the intermittent power plant as a supply-side unit. Here the wind plant is dispatched in merit order and convolved into the LOLP calculation with the conventional units. Because wind plants have no fuel cost and a very small variable O\&M cost, they will invariably be dispatched first and all available wind power will be used. The result is that the generators operating on the margin, the load-following units, will have a reduced output level. The clear advantage to this approach is that the wind plant is convolved into the reliability calculation. There is also the intellectual appeal that wind power is treated in much the same way as the conventional supply-side units in the commitment/dispatch process rather than as a load modifier.

In LDC models, specifying a wind plant as a supply-side resource causes the hourly wind power to be averaged across the sub-period. This process can be interpreted as calculating the expected value of the available wind generation during the period and thus, may be reasonable (given sufficiently good data) for long-range planning studies. Clearly, however, this approach is not adequate for calculating the shortterm (hourly) effects of wind power on the conventional generation system, because the detail data is lost. Also, this simplistic supply-side method makes it difficult to properly account for the stochastic property of the wind resource or for additional ramping that might be imposed on the remaining generators. For 
these reasons, this form of the supply method of modeling wind power plants is difficult to justify and is not presented in this study.

Another supply-side variation provides a way to assign more realistic probability levels to the wind-power availability. This variation involves using a representation of the wind power plant that has less hourly information than the load-modification method but contains availability rates that correspond to measured wind power distribution at the site. The wind power plant is modeled as if it were a conventional, multiblock thermal unit with each block having its own availability (or conversely, its own forced outage) rate. This provides a better measure of overall reliability but sacrifices the accurate time scale representation of the wind power plant.

Milligan and Miller describe this approach, called the "PR" method hereafter. Using a preprocessor model of the wind power plant, we develop one typical day per month. For each of the 24 hours in this typical day, a probability distribution is calculated based on the wind power output during that hour for each day of the month. This approach yields one probability distribution for each hour of the typical day. Each of these probability distributions is then modeled as a 10-point curve and provided to the Elfin model. Each point on the curve represents a particular level of wind power output, along with a probability of attaining that level of output. The procedure is based on the modeling of a thermal unit, providing output and forced outage data for each capacity block. The advantage of this approach is that the wind resource variability is accounted for in the reliability calculation, which is a drawback with the load-modification approach.

Figure 3 illustrates the process. The graph shows a stylized day in January for the WC site fit to a Weibull probability distribution. The probability surface shows wind speed, and is shown as a series of 24 probability distributions: one for midnight, another for 1:00 A.M., etc. These distributions are convolved with the wind turbine power curve, resulting in a similar set of probability distributions for wind power output for the month. A 10-point curve is then formed on the basis of various power-curve properties such as cut-in speed, rated output, and cut-out speed. This is then fed to the Elfin model as a series of time-varying probabilities for the month that describe the availability of wind power.

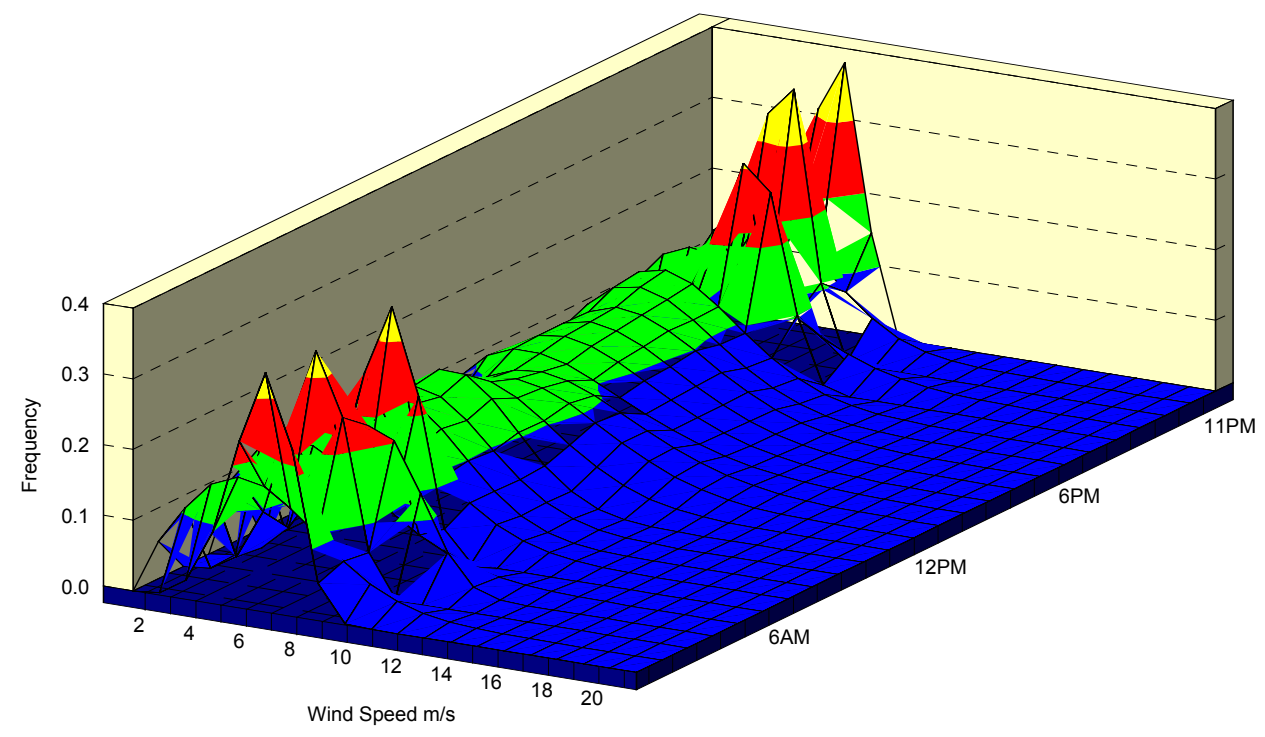

Figure 3. Site WC—Weibull surface, typical day, January 
The specification of the wind plant as a thermal, multi-block generator changes the way in which the commitment and economic dispatch of the wind plant is carried out, compared to the load-modification method. In this case, the LDC is calculated and all generators, including the wind plants, are ranked in merit (usually least-cost) order. To meet the commitment and spinning reserve targets, the Elfin model begins by selecting the least-cost generator. That is generally the wind plant. Then each of the simulated blocks of the wind plant is convolved into the various expected energy, capacity, and reliability measures. The reliability measure, therefore, accounts for the wind variation, but loses much of the hourly variation.

Unfortunately, it is not possible to predict the relative performance of the two supply-side modeling variations, either with respect to each other or with respect to the load modifier approach. The supplyside methods can result in either higher or lower LOLP calculations, depending on the characteristics of the system that is modeled.

\section{Probabilistic Time-varying Artificial FORs with Elfin: Modeling Results}

Using the PR method, we ran the same set of cases as in the earlier section using the LM method. The results appear in Figure 4. As before, we see significant differences between utilities and wind sites. Differences between wind turbines are relatively small. In comparing the PR graph with the LM graph, we see that the probabilistic cases show significantly lower benefit to the wind plant. There are a couple of reasons for this. First, as the LDC is convolved for each probabilistic block of wind capacity and energy, the model recognizes a non-zero probability that the calculated level of wind power and energy will not occur. The statistically expected shortfall, as measured with respect to the load-modification method, must be compensated for by other generators, increasing costs (again, relative to the LM case). The second reason for the difference is that during high wind-power hours, the LM method does not need to draw upon units with high dispatch cost as often as the PR method does. This is because the PR method "smears" the high wind-output hours over the 10-point probability distribution and, therefore, must call upon more high-cost generators to meet the commitment and spinning reserve targets. The bottom line: the PR method shows a lower value for wind-generated electricity than does the LM method.

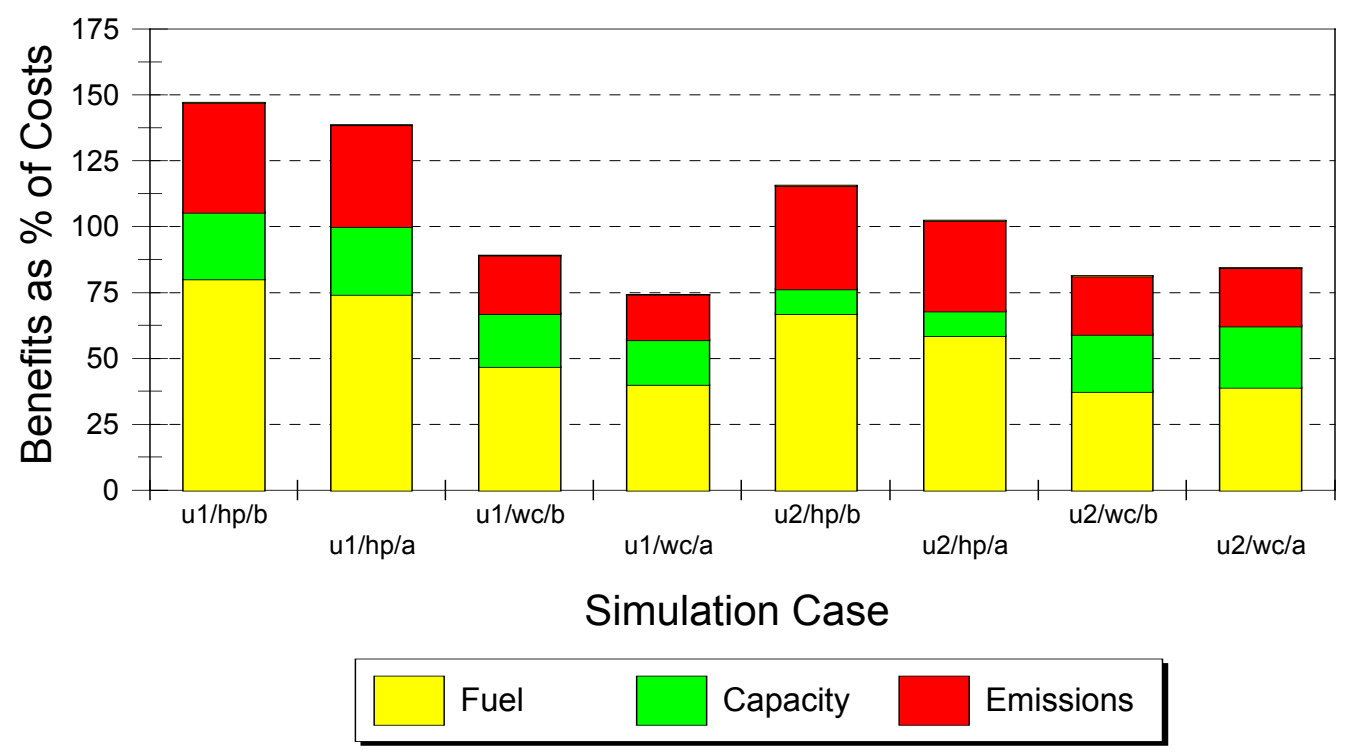

Figure 4. Benefit breakdown, method PR, $\$ 1,000 / \mathrm{kW}$ 


\section{Chronological Production Cost Models: P+}

Milligan ${ }^{13}$ compared chronological modeling and LDC modeling of wind power plants. The $\mathrm{P}+$ model is a chronological model derived from the Power-Sym model, developed at the TVA. The model, commercialized by the P Plus Corporation, has undergone many enhancements.

It can be important to model wind power plants in a chronological framework because wind varies through time. This chronological variation can be captured by an LDC model. However, optimal resource scheduling becomes more complicated when wind is added to the mix of electricity sources. Probably the most significant reason to apply chronological modeling to wind power plants is to look at the effect that wind plants have on conventional generator unit-commitment optimization. Once a unit is committed in the LDC framework, it cannot be decommitted until the end of the period, usually one week. Chronological models, however, can decommit a unit dynamically, subject to minimum uptime and minimum downtime constraints. Another issue concerns possible excess cycling of conventional units that might be caused by extreme chronological variations in wind power output. Should the wind cycling exceed that of the ramping ability of conventional generating units, the benefit provided by the wind plant would be diminished or possibly eliminated.

Figure 5 shows the cumulative wind power distribution of a hypothetical wind power plant of approximately 1,000 MW, based on actual wind-speed data. Hourly power output was calculated first, followed by the first difference of power between successive hours. The resulting data were then sorted and the result is graphed. The curve is symmetric. Reading the vertical axis at $500 \mathrm{MW}$, we see that hourly average wind power output increased by $500 \mathrm{MW}$ or more approximately 15 times during the month. Both tails of the distribution show that the wind power increased or decreased by $25 \%$ or more of its capacity within an hour's time about 80 times $(11 \%)$ in a month. This indicates that although large swings in wind power are possible, they do not occur with high frequency given this small sample. While these preliminary results justify a utility's interest in precise estimates of the effect of ramping on its loadfollowing units, they suggest that the problem may not be severe and warrants further examination. It seems clear that chronological modeling is the appropriate tool to apply to such a problem.

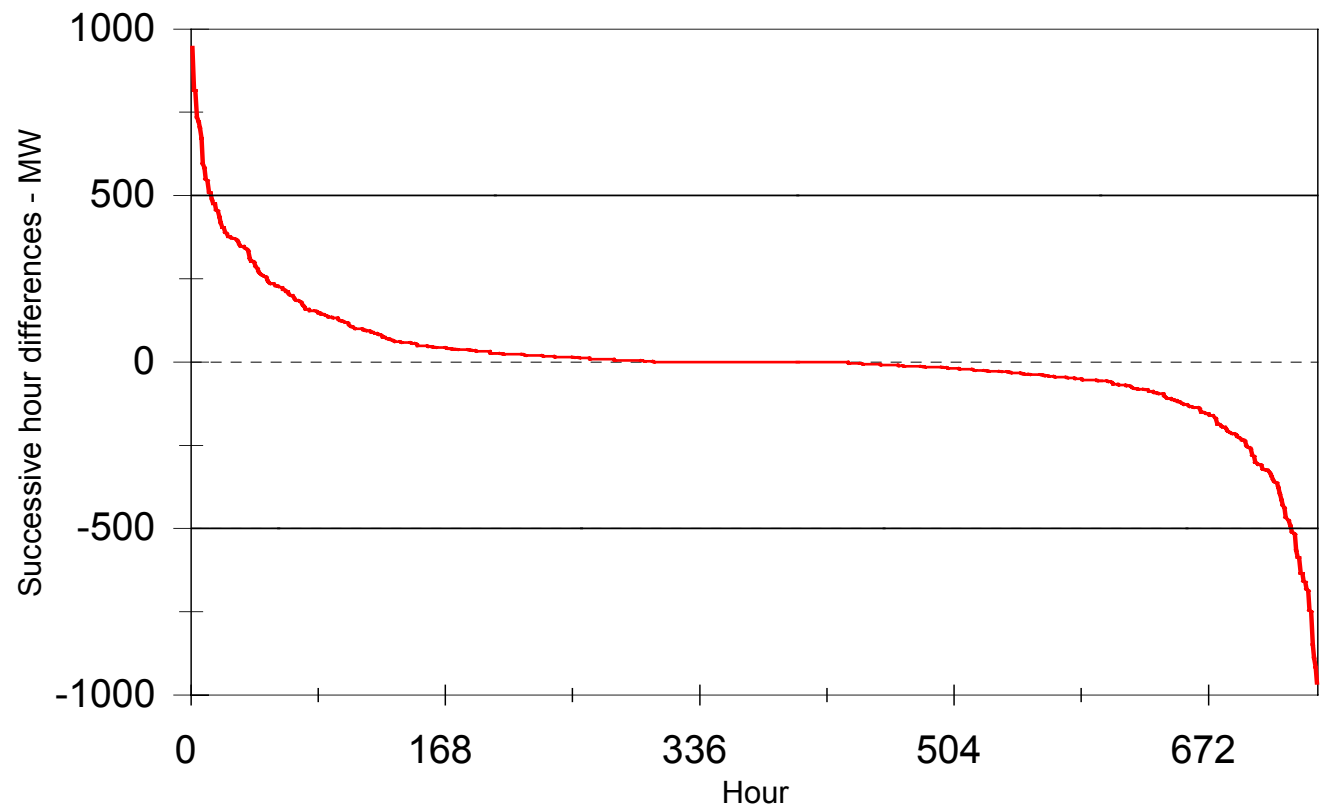

Figure 5. Cumulative wind power difference distribution, site HP, July 
The $\mathrm{P}+$ model actually contains several separate programs. The P-Month and P-Week programs are the chronological production-costing programs that produce output for the hour, day, month, and year. These programs use the same algorithm but different time scales. There is a separate module that is the reliability tool; this was not analyzed. However, the production-cost modules do produce an estimate of loss-of-load hours for various time periods using the method of cumulants. This method uses a function of the moments of the probability distribution of the load rather than a piecewise representation of the effective load curve, and is described in $\mathrm{Rau}^{14}$.

Generator types allowed by $\mathrm{P}+$ include thermal units, combustion turbines, hydro, energy storage, and transactions/interchanges. Commitment and dispatch occurs in sequence by type, beginning with transactions, observing fixed energy constraints, and dispatching in merit order. Previously committed units are used and minimum uptime and downtime constraints are enforced. The default mode of operation is probabilistic, similar to that of the Elfin model. The probabilistic option convolves each unit with respect to its forced outage rate. This is similar to applying the LDC approach to each hour because the algorithm does not account for lumpy start-up costs. The $\mathrm{P}+$ model also contains a Monte Carlo option that makes random draws representing the outage state of each unit. Although this approach is computationally much more intensive, it is useful in estimating the mean and variance of the model outputs. A third option is called "branching" and allows the user to specify a generator as the branching node. Each outage state of the branching node is simulated, followed by convolution of the other units with the probabilistic simulation algorithm. This method allows the user to focus on outage effects of particular units while retaining the probabilistic approach for the other units. The "branching" method represents a more computationally efficient method than Monte Carlo, but may be less accurate; however, it is (in the limit) more accurate than the strict probabilistic approach.

Transactions can be specified on the basis of user-defined sub-periods. These sub-periods are typically defined with respect to the utility's definition of peak, off-peak, super-off-peak, etc. The P+ model provides a variety of options for shaping a transaction with respect to peaks and valleys. Load modifications for demand-side management (DSM) or intermittent resources can be modeled as transactions.

Thermal units are modeled using capacity, heat rate, fuel price, and availability data. A separate module can optimize maintenance scheduling by levelizing the reserve margin. Thermal units can be modeled as multiblock units, with 4-5 blocks as a typical maximum. Probability levels are fixed through time, but the block ratings can change hourly. The $\mathrm{P}+$ model explicitly considers unit ramp rates, providing for a more realistic picture of generator operation. One major strength of $\mathrm{P}+$ is its fuel logic, which considers constraints on fuel delivery and storage.

\section{LDC and Chronological Model Comparisons: Commitment and Economic Dispatch}

Unit commitment refers to making a generator available for economic dispatch. Economic dispatch is the process of choosing from the available (committed) resources in such a way as to minimize generation costs. To dispatch a unit, the unit must be running and synchronized to the grid. Should an outage occur on another generator, a committed unit would then be available, subject to capacity and ramping constraints, to pick up the load and avoid a system disturbance. A generating company must decide whether or not to commit a unit for the load period, and this decision is normally made one day ahead of the load period. If the unit is not committed, then it will not be available during the load period unless it has a relatively short start-up time. Units such as combustion turbines have very short start-up times and can be committed at or near the point of economic dispatch. Slow-start thermal units, such as coal plants, may have starting times of at least 6 to 10 hours, depending in part on how long the boiler has been 
cooling and cannot be dispatched unless committed. Clearly, the commitment and economic dispatch decisions are inextricably linked.

The unit commitment methods used by these two models may seem similar on the surface, but the chronology of the respective models can cause significantly different commitment effects, especially during off-peak periods. The Elfin model asks the user to specify a commitment target, which can be any combination of percentage of load or adder to load. Weekend commitment targets can be specified separately, and the commitment algorithm proceeds accordingly. The commitment order is based on the expected average variable cost of each plant at its most efficient operating level. This average cost can, at the modeler's option, include variable O\&M costs and emission penalties. The committed capacity is reduced by the forced outage rate, resulting in an expected capacity level for the plant. Elfin performs its unit commitment routine once during the week and once on the weekend. The unit commitment is based on the peak sub-period, and commitment levels are not changed during the week. Weekend commitment is based on the weekend peak and does not change during the weekend. Because quick-start units count toward the commitment target, they are available without necessarily being dispatched. If the utility has sufficient quick-start units, it is possible that the slow-start units can be ramped down so that no excess capacity exists during minimum load conditions. If a utility depends heavily on slow-start units without much quick-start capability, then during minimum load periods, the Elfin model may not be able to reduce spinning capacity enough to avoid dump energy. In this case, a significant level of wind power during minimum load could be useless to the utility. The utilities modeled herein had sufficient quickstart capacity, so there was no dump energy. The Elfin model does a reasonably good job in capturing some of the issues surrounding the unit commitment problem. However, the convolution approach used in LDC modeling is not able to handle issues such as ramping constraints, start-up costs, and downtime minimums.

A somewhat peculiar anomaly in commitment can occur with LDC models under certain unusual conditions. Because commitment is based solely on the peak period, a significant reduction in available resources during an off-peak period can cause a commitment deficiency off-peak, even though the commitment target was met during the peak period. For example, if a firm contract with a neighboring utility provides for capacity during the system peak, and if that capacity is only available for the peak, then off-peak commitment may not be sufficient to cover the target. To solve this problem, additional capacity would need to be committed during the peak, which would result in excess committed capacity on-peak for the off-peak target to be met.

Elfin's economic dispatch routine maintains consistency between chronologically adjacent sub-periods by simultaneously dispatching across the sub-periods. Chronology is only observed at the sub-period level, keeping the model from making illogical dispatch decisions, such as dispatching a slow-start plant in the morning and afternoon but not during the midday. Dispatch proceeds in merit order, subject to must-run constraints. Upper blocks of slow-start thermal plants are counted toward spinning reserve if those units are committed; they are dispatched in economic order along with other units and blocks in the system. Elfin can also dispatch units that are priced at marginal cost.

The $\mathrm{P}+$ commitment logic for thermal and pumped storage units is conceptually simpler because the model proceeds chronologically. Fixed-energy transactions are dispatched first, followed by hydro and limited energy resources, and finally, thermal and pumped storage systems. Slow-start units are committed and dispatched in accordance with their ramp rates. Once a unit is committed, it is subject to minimum uptime and downtime constraints, which can be enforced directly in the chronological framework. The accuracy of the commitment process is quite good, because the target is a function of chronological load. After commitment and dispatch have been calculated, the model checks to make sure that no contract fuel violations have occurred. Should a violation occur, $\mathrm{P}+$ adjusts its commitment schedule within the fuel delivery and storage constraints specified by the user. 
The P+ model's use of cumulants is likely to reduce the accuracy of the calculations near the tail of the LOLP distribution. This effect is probably insignificant during most of the convolution cycle, but is a possible contributor to inaccuracies in the LOLP or LOLH calculation. ${ }^{15}$

There is an important similarity in the way each of these models accounts for a time-varying resource, such as wind. To best represent the time-scale variations of a wind power plant, each model calculates the load net-of-wind before starting the commitment and economic dispatch logic. The result is that it is not possible in either model to fully represent the time-scale variations of the wind power plant and specify an estimate of the probability that a given level of wind power will be available. This means that both models underestimate the LOLP by assuming that the specified level of wind power output is available with probability of 1.0 .

The two models calculate similar measures of reliability. Elfin calculates the statistically expected loss of load or LOLE. This capacity-based measure is provided in terms of the expected number of days per year that outages would occur. Elfin also calculates EENS. The P+ model calculates LOLH along with EENS. The differences in algorithms, combined with reliability results in the tail of the respective probability distributions, leads to differences in absolute reliability results from the two models. Different modeling options, such as Monte Carlo or branching, will also produce different results.

\section{Case Studies of Wind Power Plants Comparing LDC and Chronological Models}

To compare the modeling of wind power plants with LDC and chronological models, I set up a series of cases using two utilities and two wind regimes, assuming utility ownership of the wind plant. The utilities and wind sites are the same as those discussed above. The model inputs were calibrated so that the results from the models matched as closely as possible, then the models were run with the various wind generation cases.

To calibrate the two models, several factors had to be considered in light of the differences in modeling style and input requirements. To hold the inputs constant between the models so that we could concentrate on algorithm differences, we used one representative week of load data per month in both models (at the time, Elfin was not capable of modeling the full 52-week year). Although this would not be an approach used by practitioners of chronological modeling, allowing the two models to utilize different descriptions of system load would have introduced another source of variation.

Certain power purchase and exchange contracts were simplified in both model data sets to facilitate comparison between inter- and intra-model runs. In the $\mathrm{P}+$ data set, we did not specify ramp rates for the slow-start generation units, because that data was unavailable. Although including these rates would provide greater accuracy, these chronological results are a "best-case" measure of power production costs, assuming no chronological constraints of power plant operation and ramping.

I provided both Elfin and $\mathrm{P}+$ with 8,760 hours of wind generation for the year. Elfin performs a subperiod averaging routine so that each month's data are averaged into a typical week; the chronological model $\mathrm{P}+$ dispatches each typical week four times, using a full month of wind generation. We can interpret these time-scale differences as follows: Elfin calculates average wind power, dispatches one typical week per month, and then scales the weekly values to the monthly values. P+ dispatches the typical week four times with the actual wind generation, which normally varies from week to week. Ignoring all other differences between the models, any variation in the outcomes of the models is due to the constraints imposed by the LDC simplification, to the extent that they exist. 
Each of the utilities in this study has units with a range of generator fuels, fixed transactions with other utilities, and qualifying facilities (QFs)-power purchases that qualify under the Public Utilities Regulatory Policies Act (PURPA) that are priced at the utility's avoided cost. The various resources, hydro, coal, nuclear, natural gas, oil, combustion turbines, and pumped storage, are summarized in the figures in the previous section. Each system was modeled with an approximation of its existing transmission constraints, but we did not explicitly consider the effect of wind generation on the existing transmission system.

This discussion includes results from two different sets of utility load data: a "high-load" case and a "low-load" case. The high-load case provides a look at the two utilities when capacity is in short supply and peak commitment targets cannot always be met. The "low-load" case examines some off-peak results for utilities that can meet the commitment target.

\section{Chronological Model Results}

We begin with some of the $\mathrm{P}+$ model results for the system peak day using the high-load scenario. Offpeak and annual results are discussed below. Figure 6 shows the hourly generation by unit type for the no-wind case for U1. For clarity, purchases have been taken out of the graph. The generation is plotted in (approximately) dispatch order from the bottom up. On the bottom we see the baseload nuclear units, for which output is constant throughout the day. The "other" category includes a mix of other baseload units that also remain constant for each hour. The next level contains the gas/oil units, which clearly make a large contribution to the daily load swing, as do the hydro plants in the next level. At the top we see the small contribution of the combustion turbines, which operate for approximately 6 hours during the system peak.

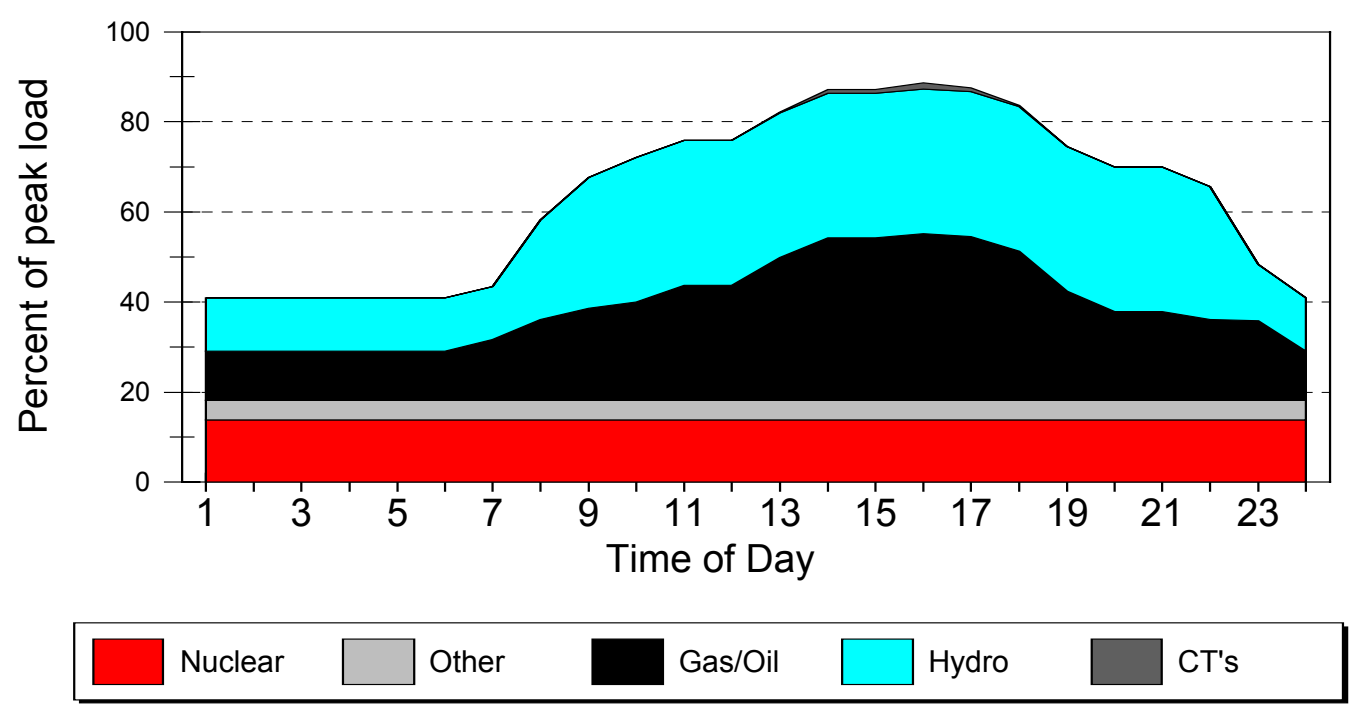

Figure 6. P+ peak day simulation, U1, no wind

The wind penetration in each system is modeled to be approximately $4 \%$ of system peak load (at rated capacity). Figure 7 shows the effect of adding the HP wind plant to the generation mix during the peak day. If modeled as a supply-side resource, wind would be dispatched first and would likely be graphed below all other resources. As modeled here, wind is treated as a firm transaction and therefore subtracted from system load prior to unit commitment and dispatch. The wind plant is graphed immediately above 
the baseload generation in each of the following figures to help clarify the constant baseload output with and without wind.

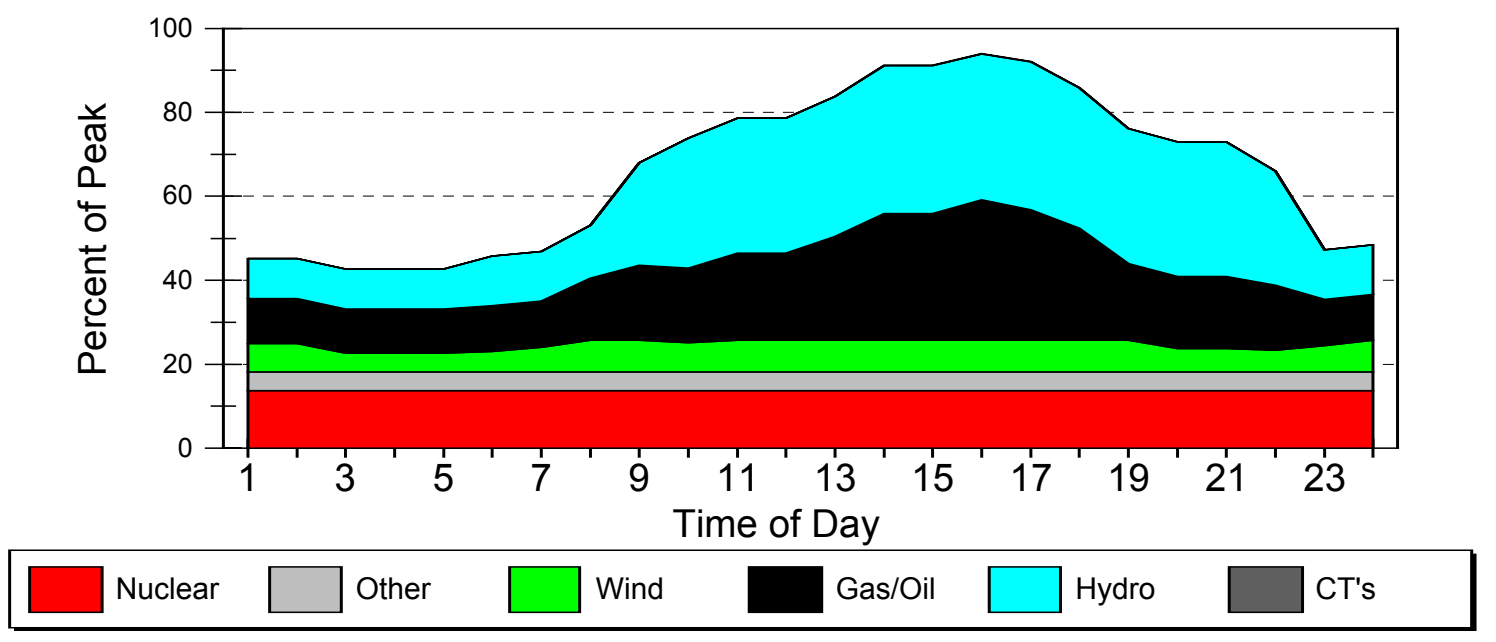

Figure 7. P+ peak day simulation, U1, WC wind

Figure 7 should dispel the notion that wind somehow offsets the generation of baseloaded units. To calculate the effect of adding wind generation (or any other type of generation) to the system, the commitment and dispatch simulations are run with and without the new generators. It is clear from these figures that the units most affected by the introduction of wind are the intermediate and peaking units not the baseloaded units. The numerical simulation results accurately show that the output of all baseload units is virtually unchanged by the introduction of wind power.

Although the output of baseloaded units is generally unchanged by adding wind energy to the mix, it is possible that, during extreme low-load periods, subject to operating constraints on the plant, baseload output may change somewhat. However, the most expensive unit should be the first to be curtailed unless constraints prevent it. It is also important to emphasize that the graphs presented here mask a great deal of detailed data and variation in generator output because of the wind energy. In the various simulations examined here, virtually all resources exhibited at least a small change when wind was introduced into the resource mix. The only exceptions are those resources and/or transactions that are fixed. For a few transactions, the total energy did not change but the timing of the transaction sometimes shifted. For resources priced at marginal cost, energy totals were largely unchanged but the system marginal cost differences resulting from wind caused a reduction in payments to the supplier. Part of the benefit that wind provides to the utility can, therefore, be traced to a reduction in payments to developers that qualify under PURPA or other purchases that are priced at marginal cost.

Figure 7 also indicates that the wind resource is effective in reducing fossil fuel consumption. However, it is important to realize that there are many complex factors that drive the wind resource and influence system loads. Figure 7 illustrates a fortuitous combination of system peak during a period of high wind power output. Figure 8 shows a contrasting case of system peak during a period of relatively low wind at the WC site. The WC wind regime generates a small amount of power during the early morning and early evening but is insignificant during the daily peak. Daily wind power from this site is not always so low during the summertime when utility U1 experiences its system peak. However, these two peak-day graphs illustrate the wide range of conditions that can occur in periods during the system peak day. 

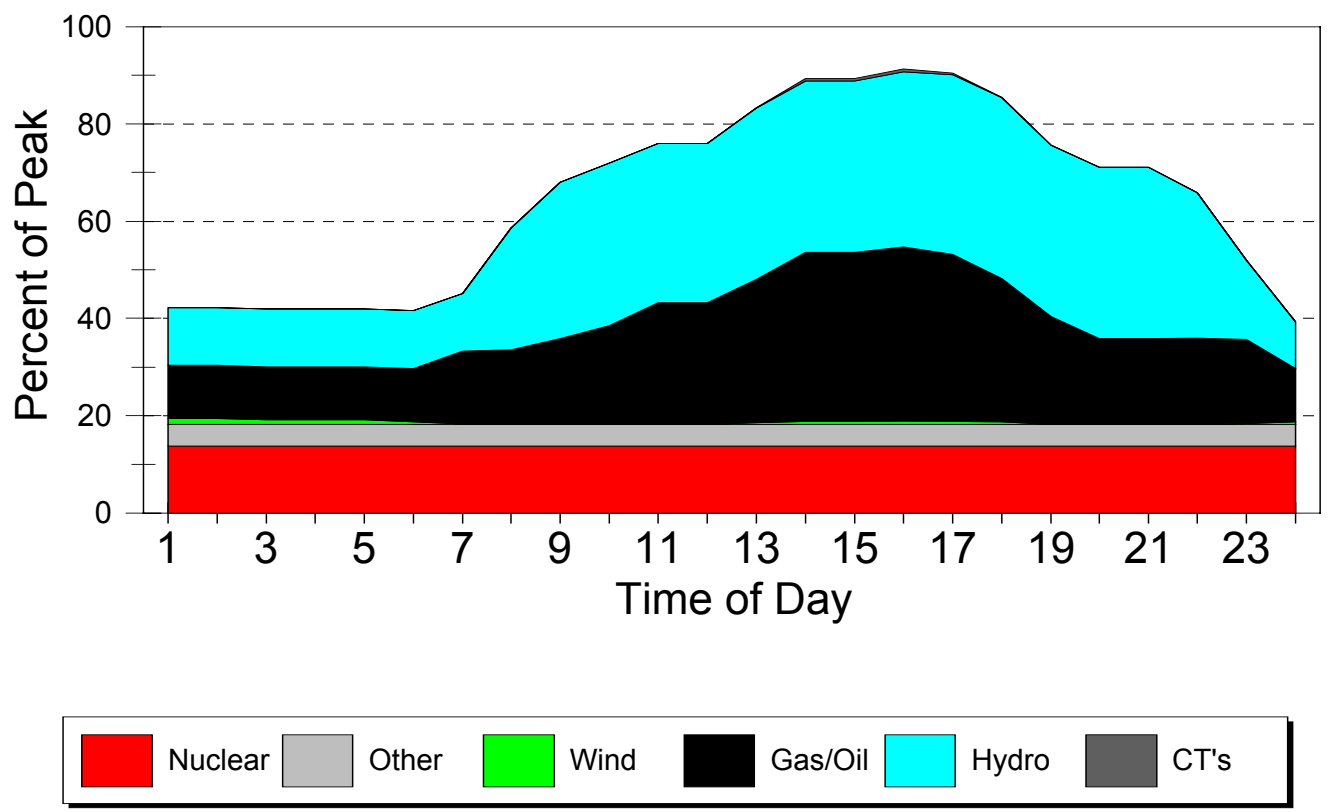

Figure 8. P+ peak day simulation, U1, WC wind

From a long-range planning perspective, it is often useful to choose a reasonable, expected (in the statistical sense) base plan, using extreme variations to test the system's ability to handle the extremes. One simple approach to constructing the expected case is to calculate an average day in the utility's peak week. Figure 9 shows an hourly graph of this average day for U1 with a wind plant at the HP site. All values are averaged across the week for a particular hour; thus, the 3:00 A.M. value on the graph is the average of all 3:00 A.M. values for the week, etc.

The hourly wind power generation in Figure 9 indicates that the peak day wind power in Figure 7, while higher than the mean for the week, cannot be regarded as atypical for the peak week. Although the average generation from the conventional resources may not be as interesting from a planning perspective, it provides an important look at the mean generation requirements for the week. 


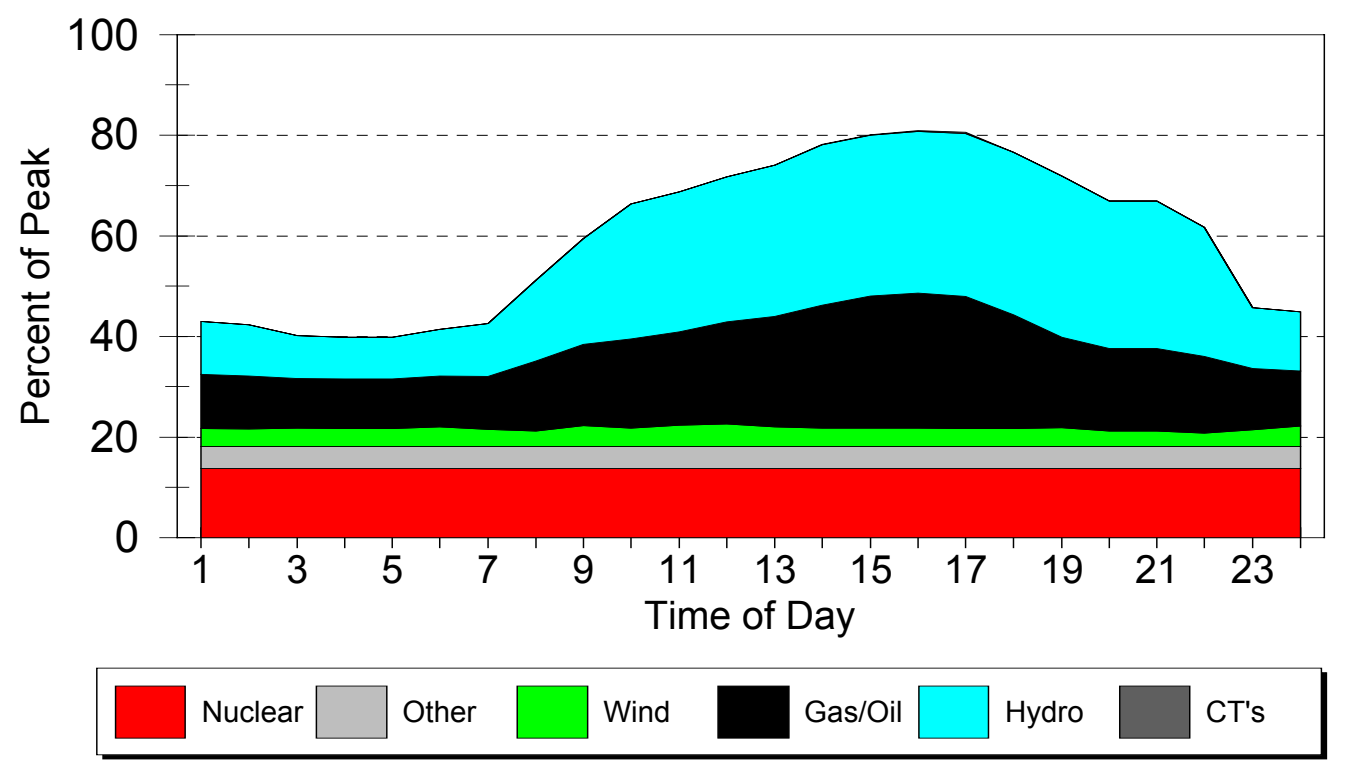

Figure 9. P+ average day in peak week, U1, HP wind

Figure 10 contains the corresponding graph for the WC site. This average condition is clearly superior to the wind power realization on the peak day; i.e., it appears that the peak-day wind power is substantially below the average daily value for the peak week. Although the wind power's contribution to the morning load pick-up is not very high, it reaches its daily maximum just before system peak and continues until just after the daily peak begins its decline.

These simulations identify the generator fuel sources that can be reduced through the use of wind power. Figure 11 summarizes the change in the major fuels as a percentage of annual energy generated. The graph shows U1 at both wind sites, using the no-wind case as the basis of comparison. Percentages less than zero indicate reductions from the base case. 


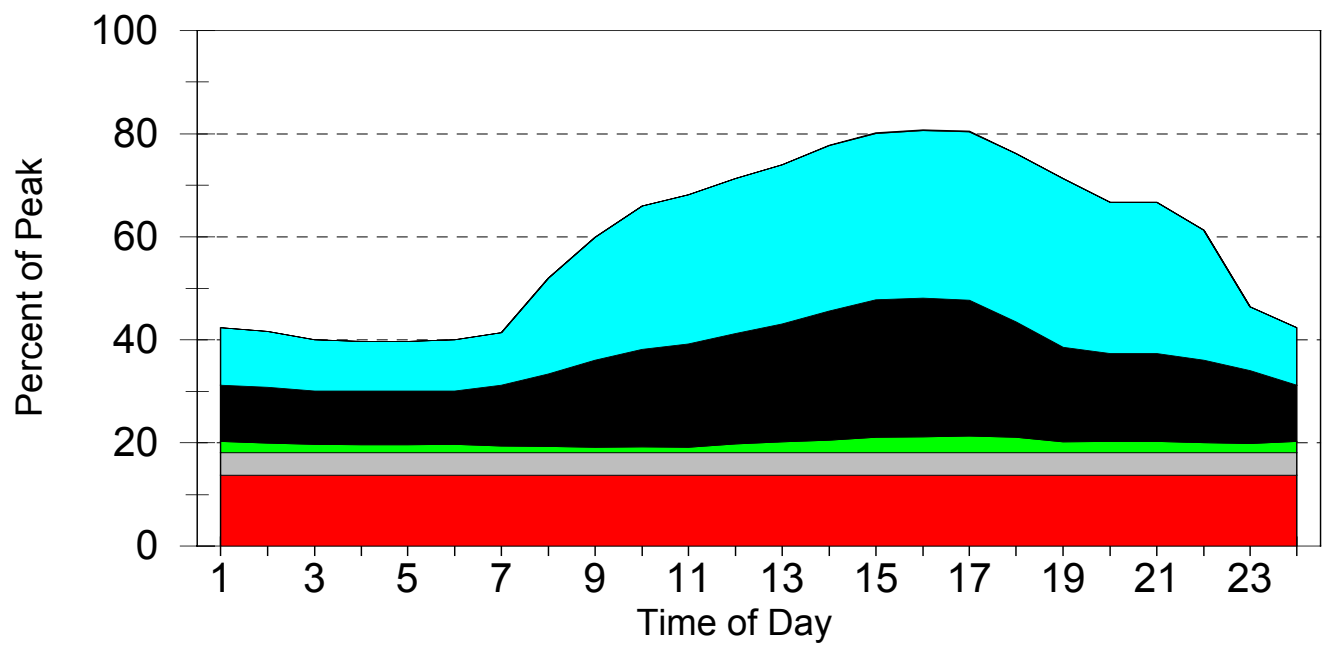

Nuclear
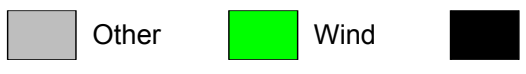

Gas/Oil

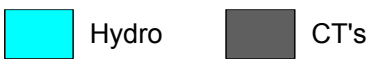

Figure 10. $\mathrm{P}+$ average day in peak week, U1, WC wind

Figure 11 shows the greatest reduction in combustion turbine (CT) and gas/oil generation. However, this percentage ranking distorts the CT generation, which is a very small portion of the annual mix of the utility. The most significant reduction is in the gas/oil units. These generators, along with the hydro units, are the ones normally used for load-following. Because wind generation is used whenever it is available, the marginal load-following unit, typically the most expensive for that hour, is reduced accordingly (last one on, first one off). The annual reduction in gas- and oil-fired generation ranges from about $5 \%$ to $8 \%$, depending on the wind regime. Baseload units experience extremely small changes, that result from low-load times when wind power is available. Because these units are usually the least expensive or are subject to must-run constraints, the change in generation is insignificant.

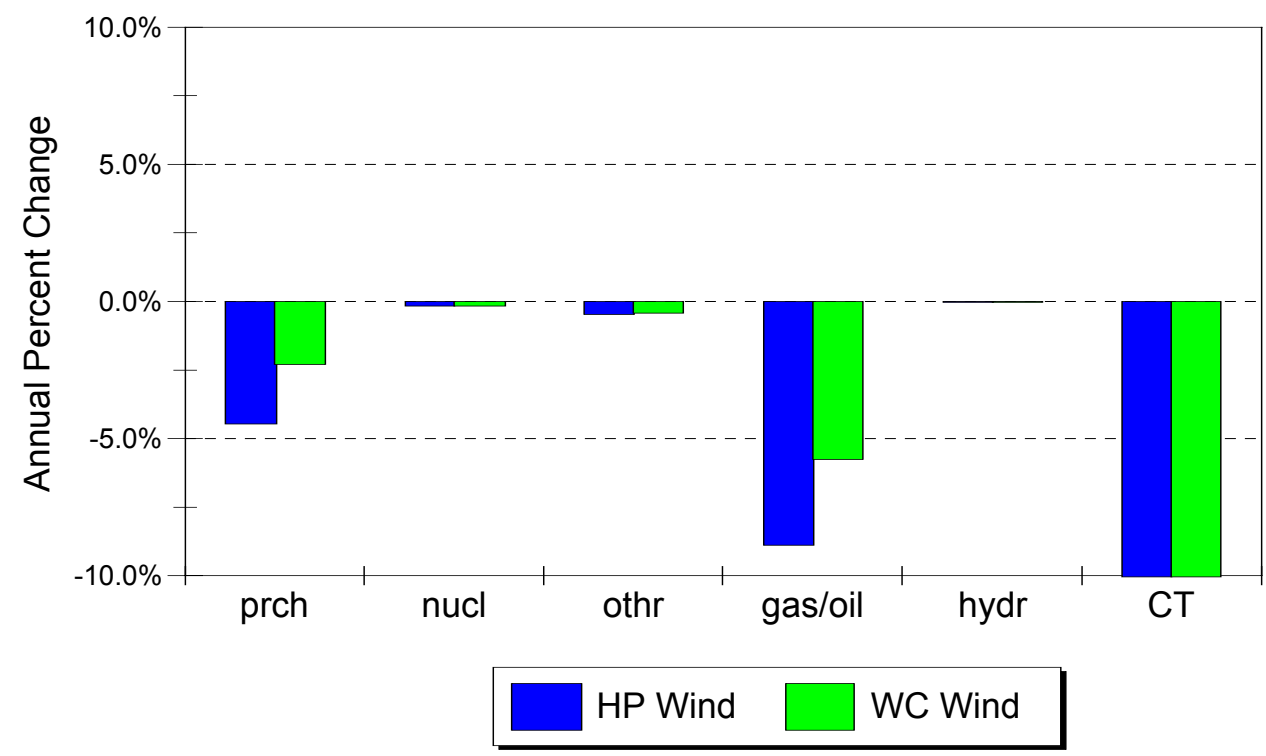

Figure 11. P+ comparison of wind and no-wind cases, change in energy generation by unit type 
U1 can also reduce purchased power by approximately $1 \%$ to $3 \%$. The ability to reduce power purchases is highly dependent on the utility and the terms of its power purchase commitments.

The wind power benefit was calculated by taking the difference between the power production cost of the base case (with no wind) and the production cost of the relevant wind case. All costs were calculated for a single year. The benefits of wind power from the HP site, as calculated by $\mathrm{P}+$, can be summarized as a $4.1 \%$ reduction in operating costs for the year and a $49.3 \%$ reduction in annual LOLH. The WC site case showed a $2.7 \%$ reduction in costs and a $65.3 \%$ reduction in LOLH. Although the HP wind provides more reliability on the peak day, the WC site does more to increase system reliability over the full year. If faced with a choice between these two sites, utility planners would need to carefully balance the reliability needs and the economic returns offered by each site. It is also interesting to note that the wind site that provides the higher level of annual reliability provides a lower level of economic benefit. This occurs because the WC site has a better correlation to annual loads than does the HP site, but the latter provides more energy and thus more fuel savings. The wind site with the highest reliability benefit may not provide the greatest energy capture.

\section{LDC Model Results}

The Elfin model produces results that are very close to those of $\mathrm{P}+$. The load-modification modeling method is used for these Elfin runs; a method that parallels the one used with the $\mathrm{P}+$ model. The benefit of wind power for the HP wind case calculated by Elfin is $4.5 \%$, and the WC wind benefit is $2.6 \%$. Because of the non-chronological nature of Elfin, daily and hourly output is not available. However, the Elfin results are consistent with $\mathrm{P}+$ in that the output of the baseload units changes insignificantly when wind power is added to the system. The output does not change for the load-following units that are on the margin during periods of wind power. The following figures show the Elfin output that corresponds to the $\mathrm{P}+$ results above. In constructing these LDCs, the capacity from each fuel type was weighted by availability, capacity, and commitment factors for the peak week (daily data is not available). Although these graphs are not precise pictures, they illustrate the overall results.

Figure 12 shows the stylized annual LDC for the no wind case. The horizontal axis represents the various sub-periods used by the model. For all of these cases, a typical week for U1 was divided into six subperiods, corresponding to its peak, off-peak, super-off-peak, etc. During a simulation run, the model actually constructs a single LDC for each of the sub-periods, performing the unit commitment and economic dispatch for each sub-period. The graphs that follow represent linear interpolations of the results of each of these LDCs. The various baseload units have constant output, whereas the oil/gas and hydro units perform the load-following function.

Figure 13 illustrates the HP wind case. The wind power plant was modeled with the load-modification method. As indicated by the diagram, the load-following units reduced their output in response to the additional wind power on the system. As with the $\mathrm{P}+$ results, the contribution of the wind plant during the system peak is significant. This is illustrated by the size of the wedge under the gas/oil generation. Of course, year-to-year variations in the wind power contribution to peak are to be expected.

Figure 14 also supports the results of the $\mathrm{P}+$ model for the $\mathrm{WC}$ wind case. Here, the diagram indicates that most of the reduction in gas/oil generation occurs during the off-peak period, resulting in a smaller "tail" for hydro and gas/oil units. This is most visible in sub-periods 4 and 6 . 


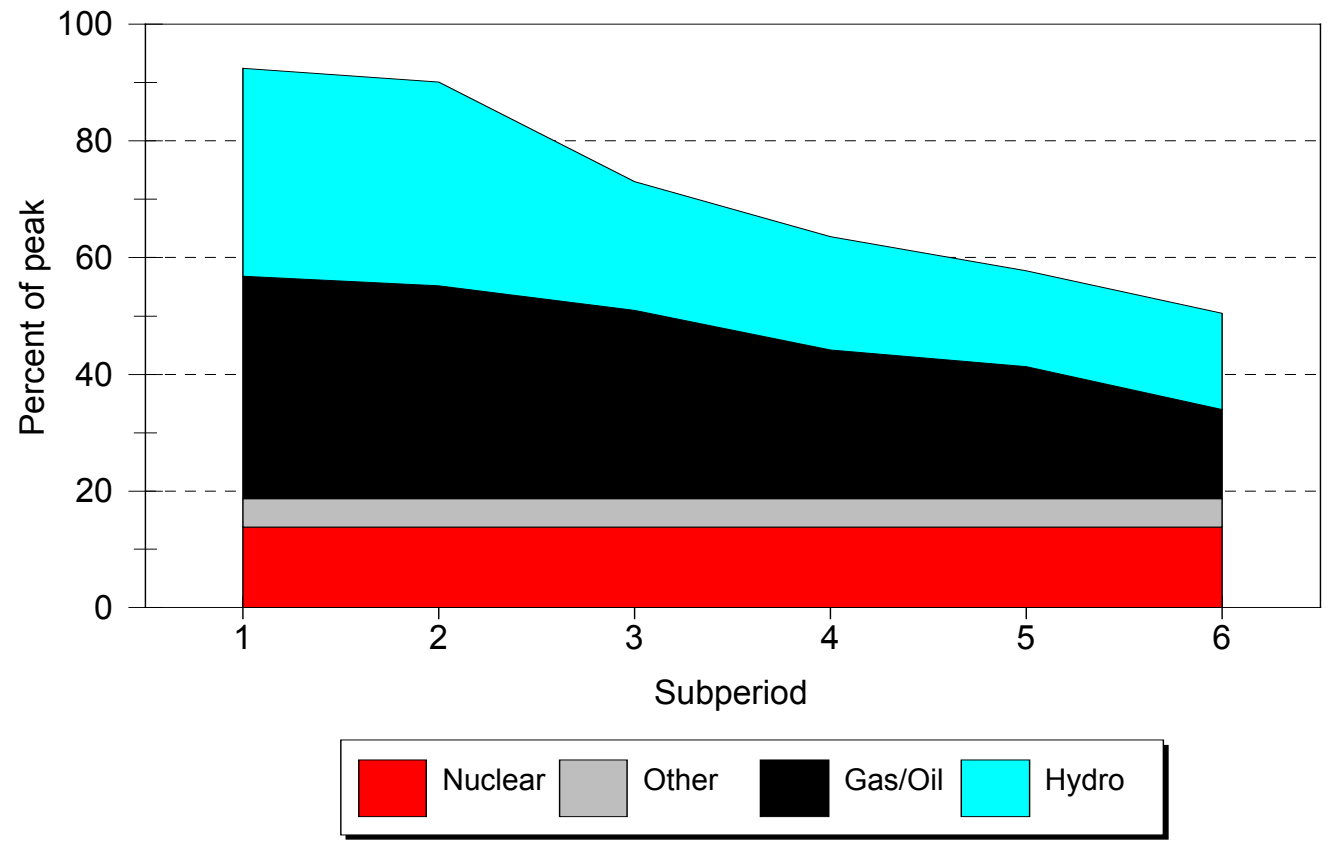

Figure 12. Elfin peak week subperiods, U1, no wind

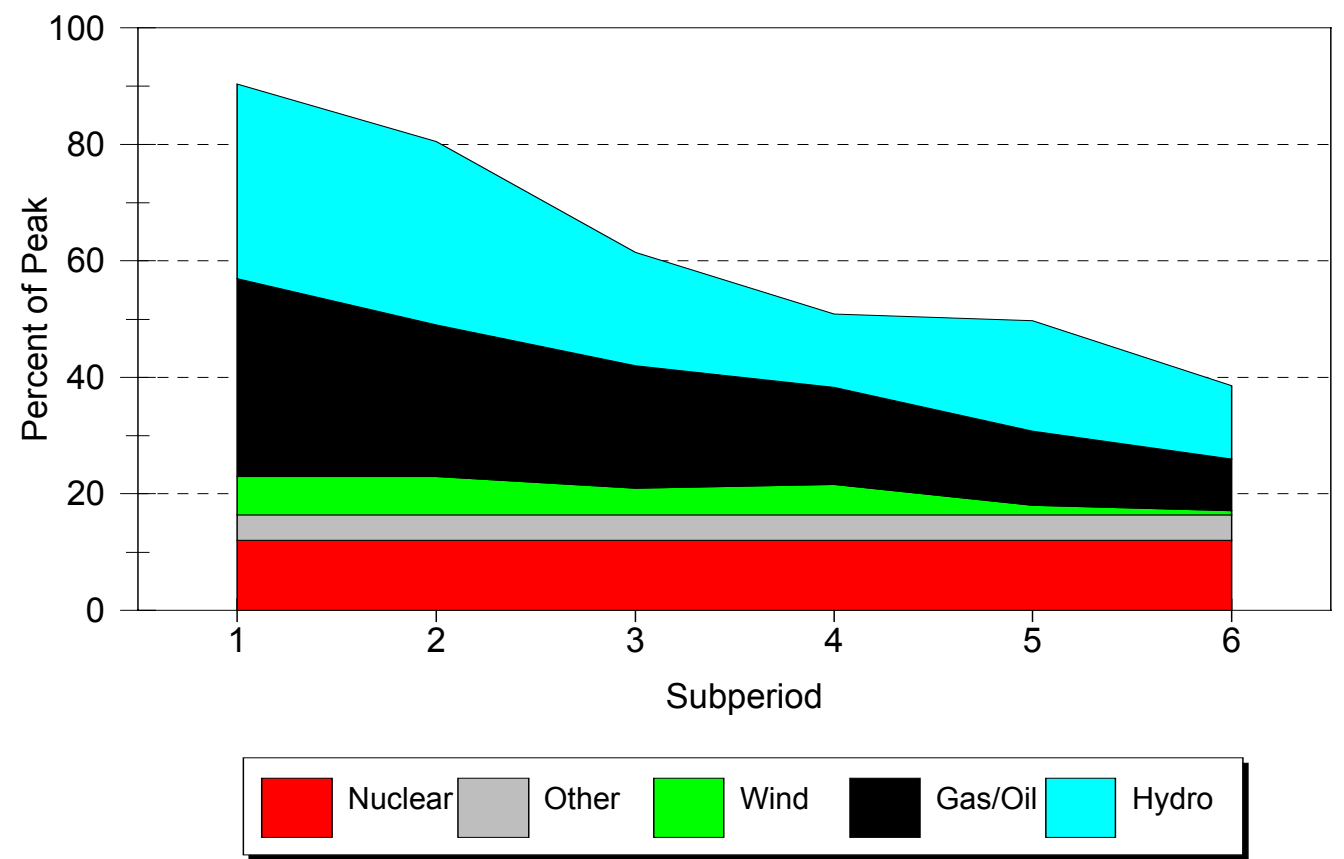

Figure 13. Elfin peak week subperiods, U1, HP wind 


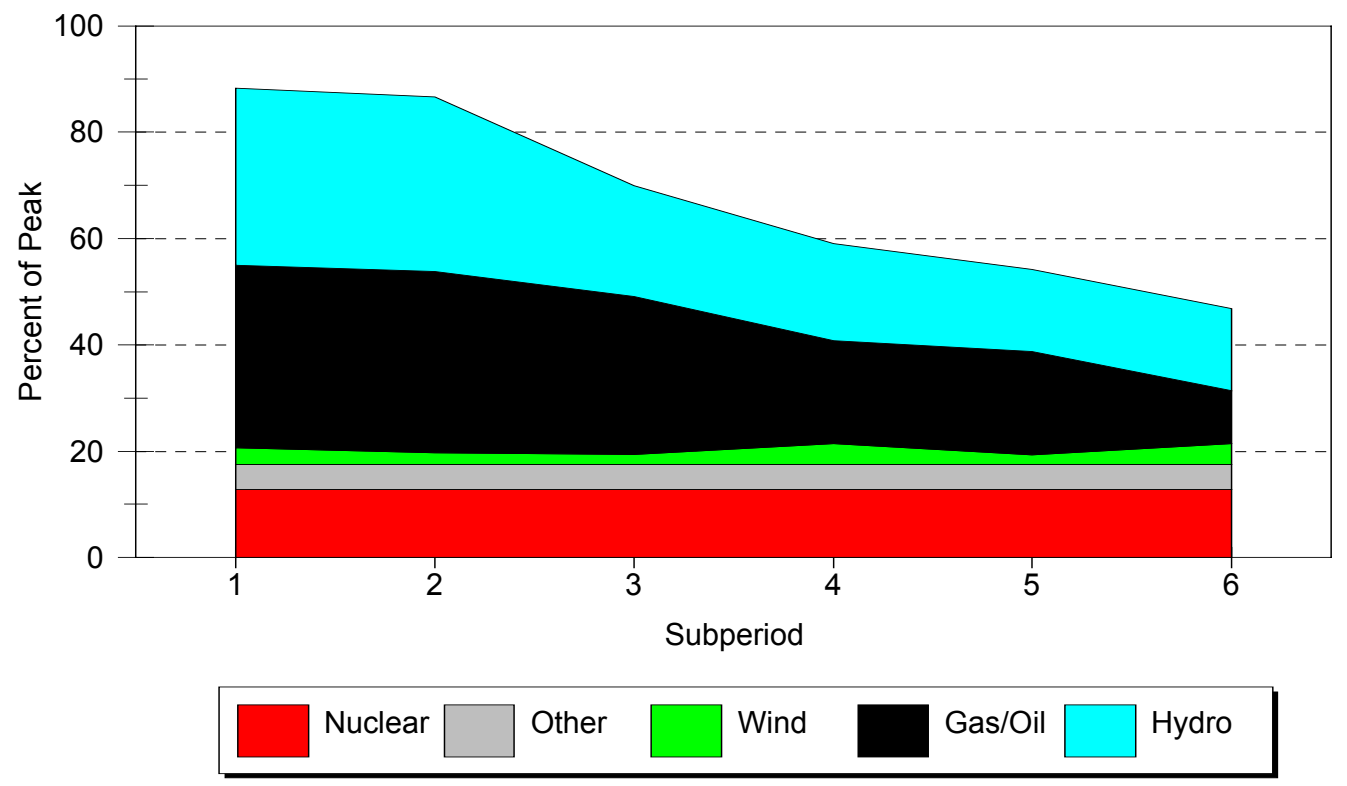

Figure 14. Elfin peak week subperiods, U1, WC wind

\section{Comparison of Model Results: Chronological vs. LDC}

By consolidating all of the methods, we produced the following sets of model runs. With Elfin, wind was modeled as a load modifier and a multi-block supply-side resource. With $\mathrm{P}+$, wind was modeled as a transaction, which is equivalent to a load modifier. Simulations were run for each of the two utilities and wind sites using the various modeling methods.

Figure 15 shows the percentage reduction in annual costs that result from adding wind generation to U1. The graph shows the results from the Elfin LM and PR methods. The last bar shows the P+ results.

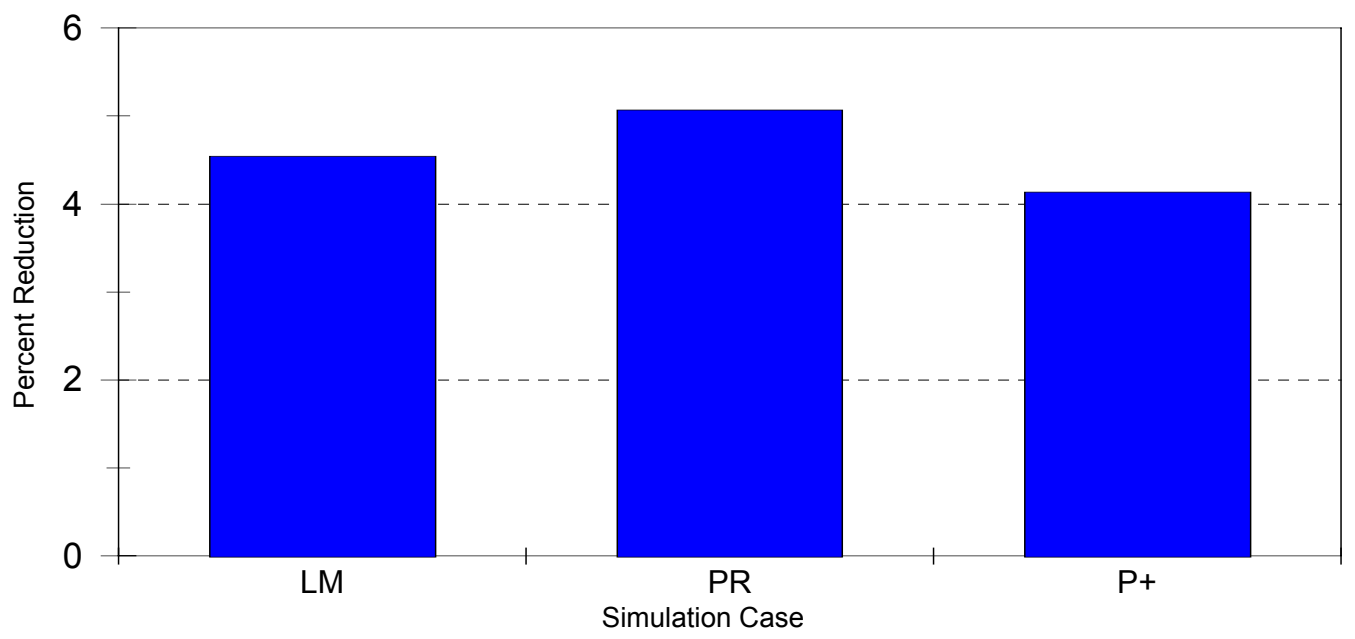

Figure 15. Percent production cost reduction from base case, U1, HP wind 
The Elfin cases clearly produce similar results-cost savings (benefits) in the 4-5\% range. Conceptually, the Elfin LM case most closely parallels the $\mathrm{P}+$ case because it offers the greatest degree of temporal resolution and deducts wind power before performing the commitment and dispatch algorithm. Comparing these two cases, we see the $\mathrm{P}+$ case shows a slightly smaller benefit than the Elfin LM case$4.1 \%$ versus $4.5 \%$, respectively.

Figure 16 illustrates the corresponding results from the WC wind site. The same relative relationships between the various Elfin modeling scenarios are apparent. The Elfin LM case yields a 2.6\% benefit compared to the $2.7 \%$ benefit of $\mathrm{P}+$.

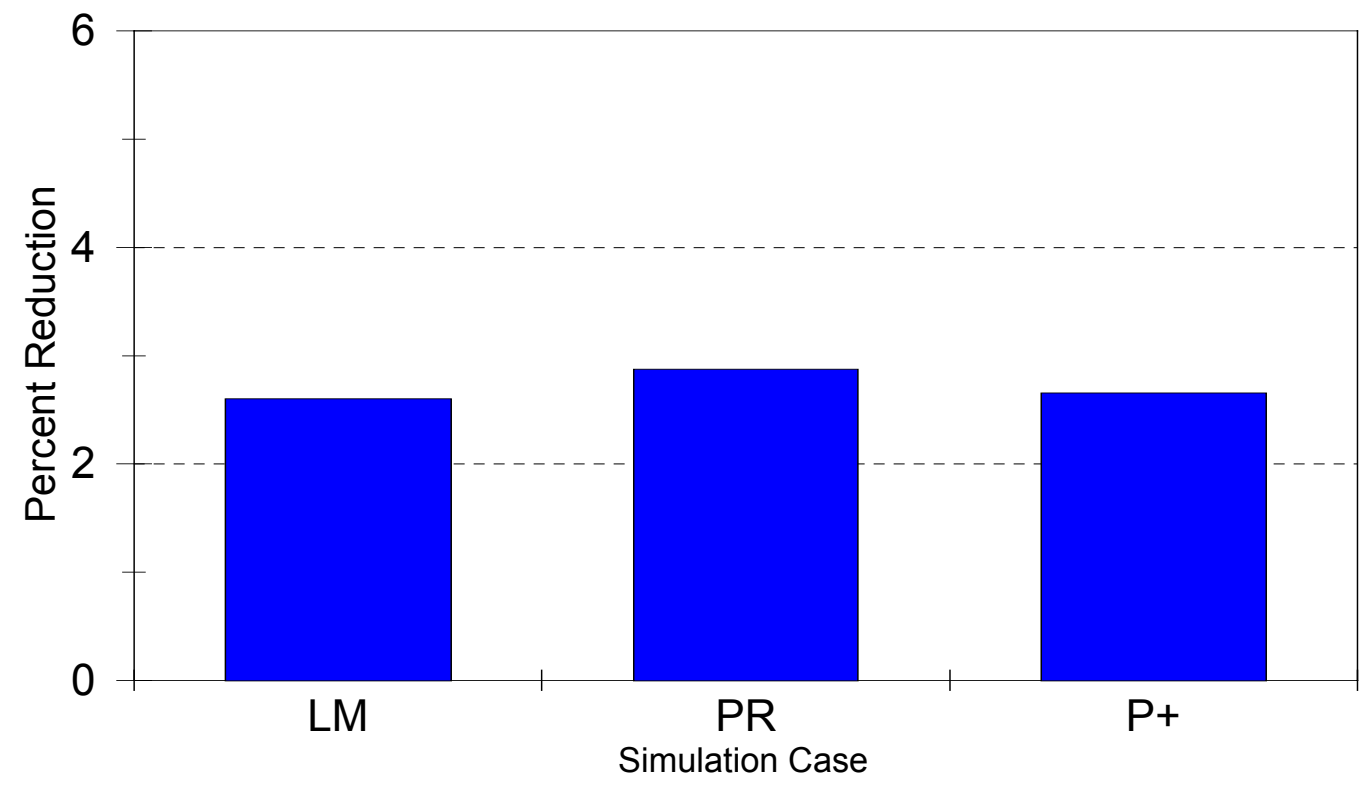

Figure 16. Percent production cost reduction from base case, U1, WC wind

The $\mathrm{P}+$ model calculates less of an economic benefit for wind power in the HP wind case than does the Elfin model. This implies that the change in generation calculated by $\mathrm{P}+$ is less than that of Elfin. Because the baseload units and combustion turbines experience an insignificant absolute change, only the load-following units, the gas/oil generators compensate for the addition of wind power. Figure 17 illustrates the change in this group of generators. Indeed, the $\mathrm{P}+$ results indicate a smaller change in the gas/oil units than in the Elfin cases.

Two hypotheses may explain the divergence in results between the two models. First, we have not provided $\mathrm{P}+$ with ramping rates; therefore, startup costs for slow-start units are not considered. The $\mathrm{P}+$ output indicates that the number of starts and stops of gas/oil units is significant - approximately 700 unit startups annually are eliminated with both the HP and WC wind for U1. Including ramp rates and other startup information would cause $\mathrm{P}+$ to calculate a larger benefit for wind power.

The second hypothesis is that, because of the chronological nature of the $\mathrm{P}+$ model, constraints on unit commitment may be somewhat exaggerated by the Elfin model compared to the $\mathrm{P}+$ model. For example, Elfin performs its commitment algorithm for each week, separating the weekdays from the weekends. Committed plants are assumed to be committed for the week, although they may be decommitted for the weekend. Although this is complicated somewhat if the probabilistic commitment algorithm is used instead of the deterministic algorithm, cost differences between these two commitment algorithms were 
insignificant. The $\mathrm{P}+$ model decommits each plant whenever possible, subject to ramping constraints. It is likely that when the Elfin commitment constraints are binding (i.e., units cannot be decommitted during low-load periods), the commitment list calculated by Elfin differs significantly from the dynamic commitment list calculated by $\mathrm{P}+$. Of course, commitment differences will lead to dispatch differences, resulting in the different cost estimates and wind benefits calculated by each model.

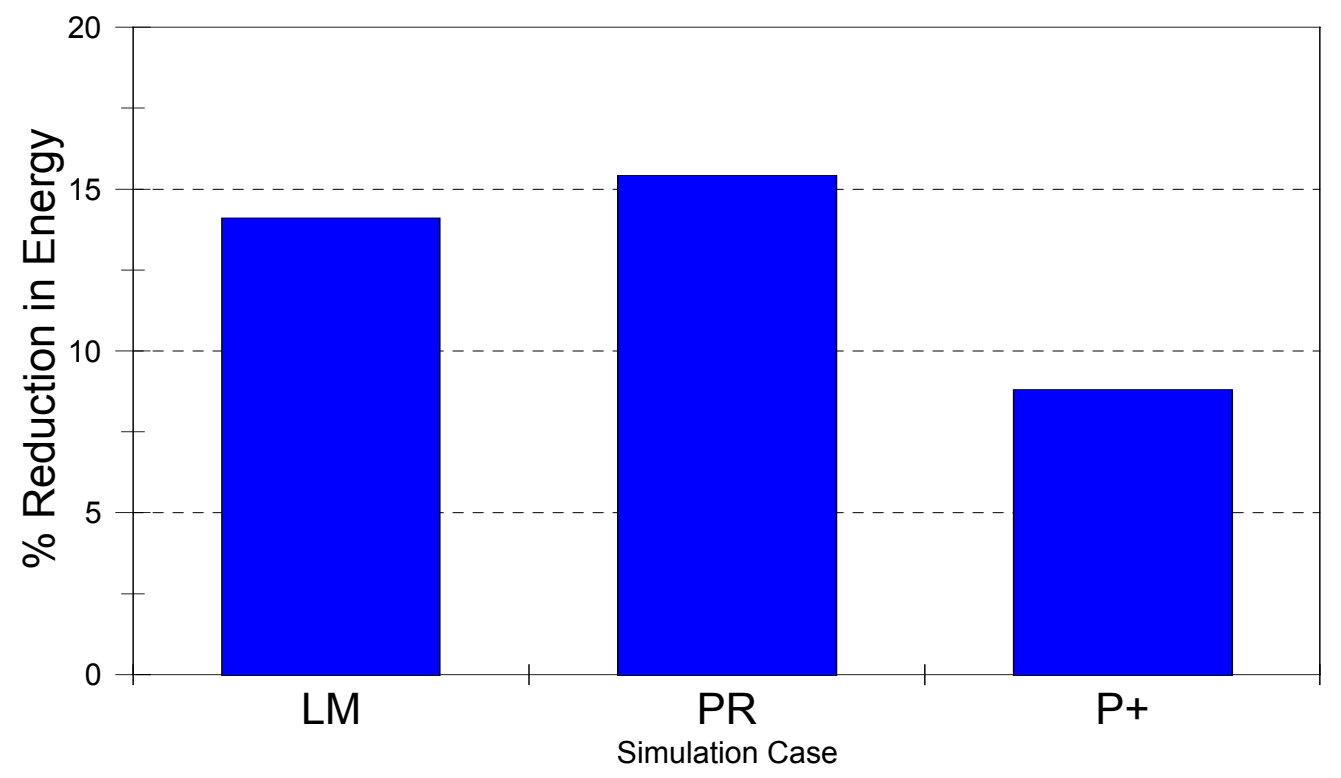

Figure 17. Percentage change in gas/oil generation, HP wind

Both models calculated the overall reliability of the system. The $\mathrm{P}+$ reliability tool was not used in this study, but the production cost module calculates operating reliability during the production simulation. The $\mathrm{P}+$ production cost program uses the method of cumulants, whereas Elfin uses a piecewise approximation to the LDC. During the model calibration phase of this project, production costs of the nowind cases for each model agreed to within about 3\%; however, the reliability measures produced by the models did not agree to within an order of magnitude. The relative changes in reliability that each model calculated as a result of adding wind generation was surprisingly close, as indicated by Figures 18 and 19. It is difficult to interpret this percentage reduction without resorting to capacity credit measures, such as effective load carrying capacity discussed in Part 2 of this paper. This is because the utilities' baseline reliability level is typically 1 day in 10 years (based on LOLE). Any additional capacity will improve this reliability measure somewhat, reducing an already-small number substantially.

It is not clear from this exercise which of the reliability estimates is the most accurate. The accuracy of the chronological model must be balanced against the accuracy of the piecewise approximation used by the LDC model. It is clear that the relative changes in reliability induced by wind power calculated by each model are in agreement.

Although the discussion thus far has revolved around U1, the analysis and model runs also were performed for U2, and the results were not significantly different. Baseload generation was not displaced by wind power (except for extreme low-load periods), and most of the energy displacement occurred with the gas/oil units. The calculated benefit of wind power between the two models was again very close when the load-modification method of Elfin was compared to the $\mathrm{P}+$ results. 


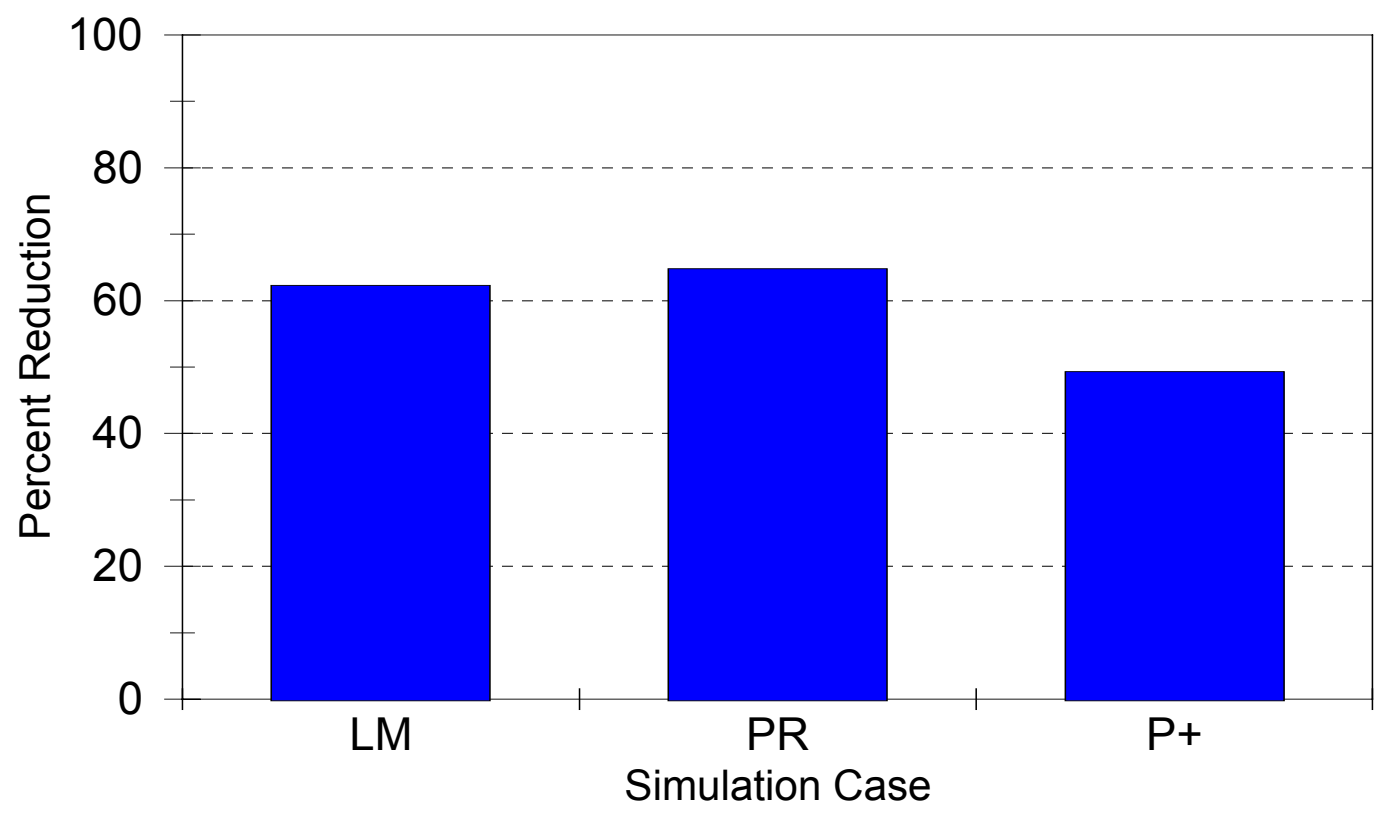

Figure 18. LOLP reduction from no-wind case, U1, HP wind

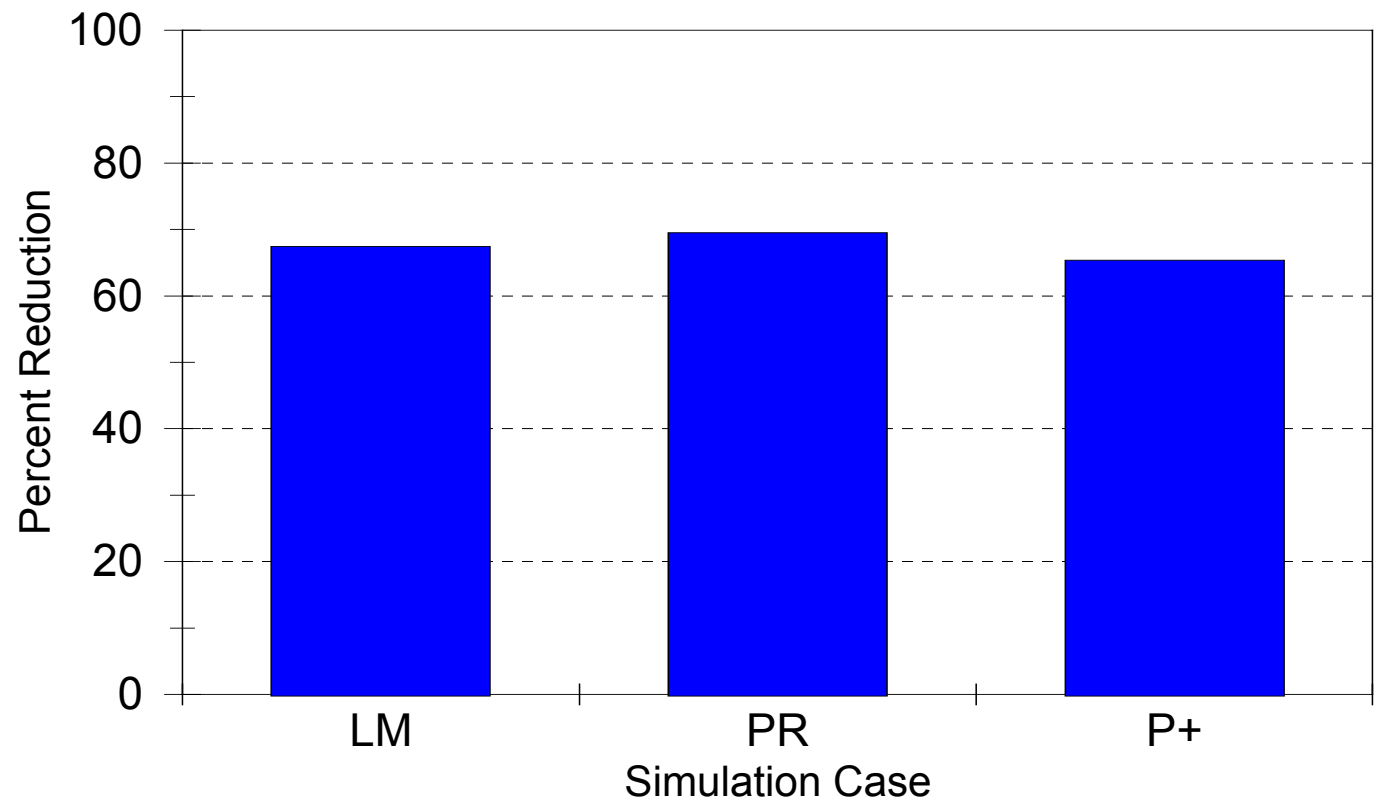

Figure 19. LOLP reduction from no-wind case, U1, WC wind 


\section{Off-Peak Results}

Much of the analysis of wind plants focuses on system peak effects and impacts. This focus results from the utility's obligation to serve its load, and the peak period presses all available resources into service. Resource needs during peak periods drive the system reliability measures. However, the choice of resources used on-peak has an important effect on off-peak costs. Given the classic trade-off between building a quick-start combustion turbine and a slow-start steam boiler, the decision maker must weigh a high-fuel-cost/low-capital-cost resource with a low-fuel-cost/high-capital-cost resource. The slow-start unit likely imposes an overhead cost-the cost of spinning at its minimum load level during low-load periods. This type of cost has long been recognized. ${ }^{16}$

Chronological transition between the peak and off-peak period occurs as the control center or independent system operator (ISO) reduces the output of the load-following units, subject to ramping and minimum run constraints. Both the Elfin and $\mathrm{P}+$ models take these off-peak periods into account, as will be discussed below. However, it is interesting to examine some plausible scenarios that can occur off-peak for a utility with significant wind generation.

From a power system scheduling perspective, the most economically advantageous situation occurs when a new wind plant can eliminate the commitment of a conventional unit. For this to occur, the wind generation must displace the conventional unit for the entire time that the conventional unit is needed. Displacement does not need to occur during the hours that the conventional unit is not needed and running at minimum load. In terms of off-peak commitment effects, this total displacement can take place only if the generation mix is not operating at its minimum load level.

The Elfin model performs its commitment scheduling on a weekly basis. Slow-start units that are needed during the week can be run at minimum load levels, but they remain committed for the week. If desired, units can be specified as weekend-constrained. The commitment target is set for each week and is typically equal to the peak load plus a reserve percentage. The commitment algorithm ensures that there is sufficient capacity from spinning slow-start plus quick-start units to meet the commitment target for each sub-period of the week. If the sum of committed units falls short of the target during the peak subperiod, this shortage will extend into off-peak periods. Injecting wind energy into such a system will not reduce conventional commitment, because the additional wind capacity is needed to meet the target. However, the additional on-line capacity will increase the system reliability level.

The $\mathrm{P}+$ model calculates commitment on an hourly basis. The equivalent load is calculated by deducting firm transactions and hydro generation. The remaining load plus reserve requirement is the commitment target. If the currently committed units cannot meet the target, the next least-expensive unit is committed. This process continues until either the target is met or there are no more units left to commit. During periods of declining load, the process works in reverse. The commitment target is calculated and compared with the committed generation. If the generation is too high, the most expensive unit can be decommitted after checking to make sure it will not be needed in the next few hours. During the latenight hours, the commitment target is equal to the load plus reserves. Even if the commitment target cannot be met during the peak hour(s), it can likely be met during the off-peak periods. Injecting wind generation into such a system could still reduce commitment during these off-peak periods.

To investigate some of these effects, I modified the utilities' loads so that commitment targets could easily be met during off-peak periods. However, these two utilities have additional constraints (voltage support, transmission, and other regional requirements) that may prevent certain units from being decommitted during low-load periods. These constraints are in addition to the normal operating constraints on certain slow-start generating units. A detailed investigation of these constraints and the extent to which wind generation can mitigate them are beyond the scope of this study. The results presented here do account 
for these minimum constraints, which translate into a reduction in the potential benefit of wind power plants.

At lower load levels, a utility will scale back the operation of its most expensive resources, to reduce marginal cost. This reduction is likely to occur each hour of the year as long as the new load is less than the original load. Because wind generation displaces generating units on the margin, it should come as no surprise that, at a lower load level, wind contributes a smaller economic benefit than it would at a highload level. Figure 20 shows this to be the case for U1. Approximately the same relative relationships hold between the various simulation cases. All of the other cases show similar results-a benefit hovering near 3\% of production cost. Comparing this to the benefits from the earlier cases, we see that the wind benefit declined from approximately $4.5 \%$ (about $\$ 0.038 / \mathrm{kWh}$ of wind energy) in the high load cases to about $3 \%$ (about $\$ 0.026 / \mathrm{kWh}$ of wind energy) in the present cases. Figure 21 shows a similar situation. The benefit of wind has declined from about $2.5 \%$ in the earlier cases to approximately $2.0 \%$ (or slightly below). The implication of these results is clear: The level of benefit that is calculated by production cost models is quite sensitive to the load forecast used in the study.

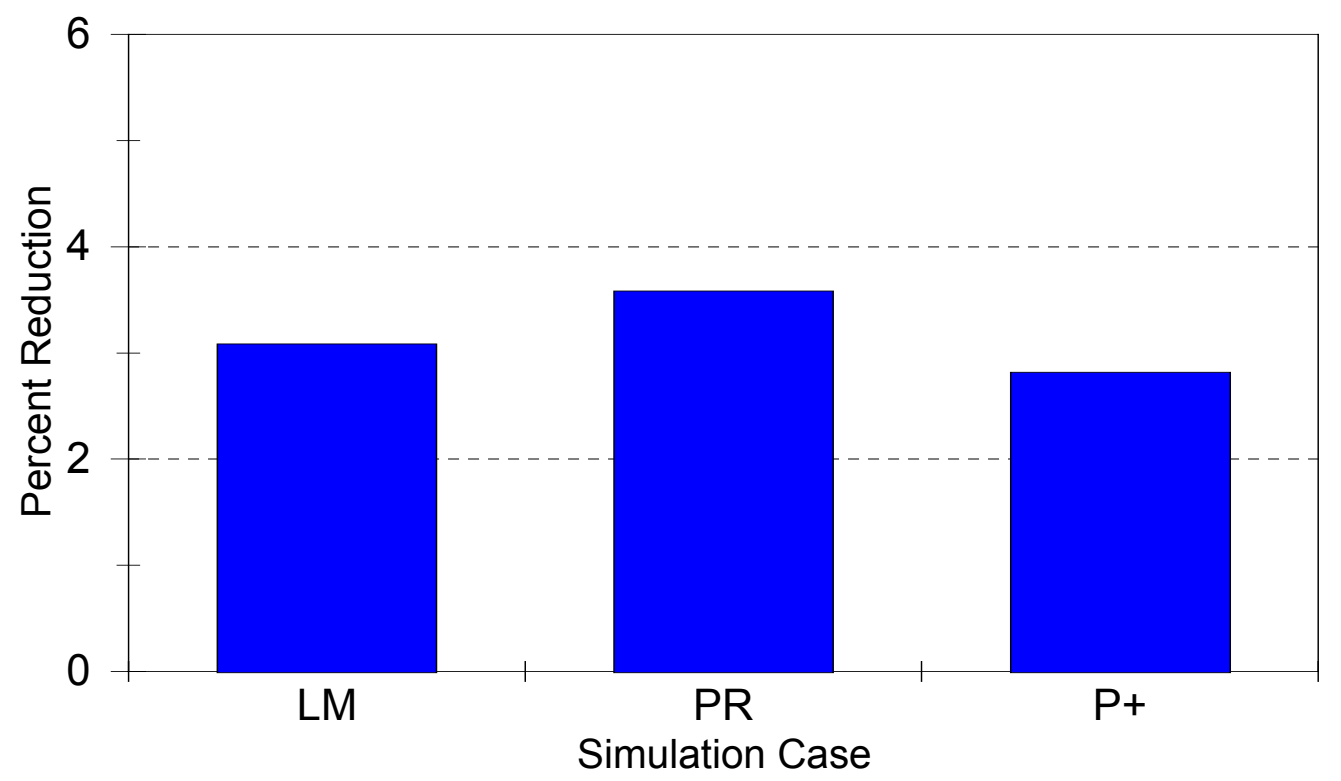

Figure 20. Production cost reduction, U1, HP wind, low-load case

To illustrate some of the off-peak results, we selected a weekend period during the peak week for U1. The HP wind resource provides substantial variation during this period, reaching both maximum and near-minimum values during the day and night. Figure 22 shows traces for the weekend in question, illustrating the wind power and utility load for each day of the weekend period. The $\mathrm{P}+$ output shows that, in general, high wind hours cause a reduction in conventional unit output. In some instances, units spinning in the no-wind case are not needed. Between 1:00 A.M. and 2:00 A.M. Sunday, the wind plant reaches its maximum output for 1 hour before declining to $37 \%$ the following hour. During the highwind period, virtually all of the spinning units are running at reduced power output, even the output of the nuclear units is reduced slightly. As wind output drops, these units spin at a higher output level. While the wind output is at maximum, additional charging for the pump storage units is possible, raising an interesting question about the value of time-shifting wind power from off-peak periods to peak periods via storage. During a few of the nighttime hours, when wind power exceeds $20 \%$ of maximum, additional spinning units can be shut down. When this is possible, the overhead cost of spinning is reduced. 
Between 5:00 A.M. and 6:00 A.M. Sunday, P+ calculated that $1 \mathrm{MW}$ of capacity had to be dumped. The wind output for that hour is approximately $20 \%$, and the dumped energy is extremely small. However, given the usual operating constraints faced by utilities, this example illustrates the potential for generating excess energy during low-load periods.

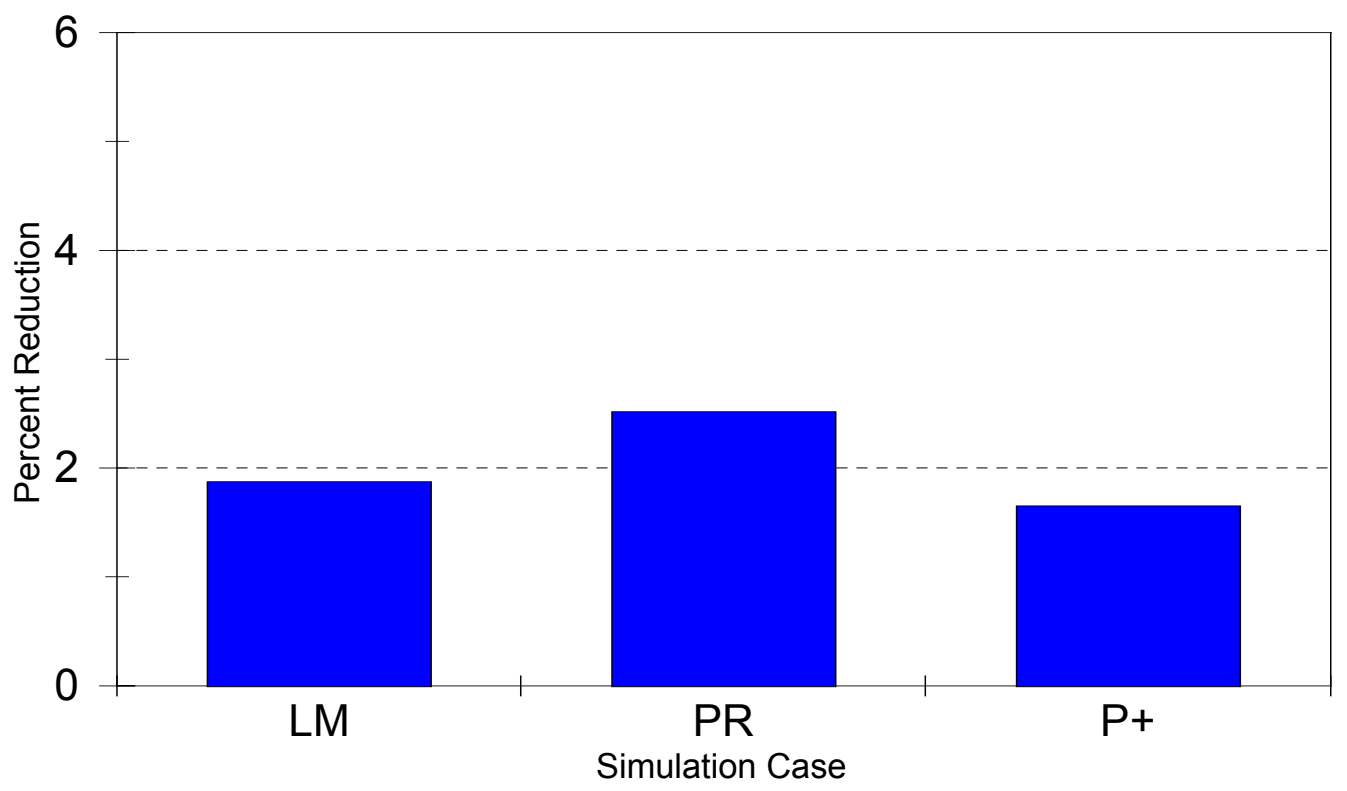

Figure 21. Production cost reduction, U1, WC wind, low-load case

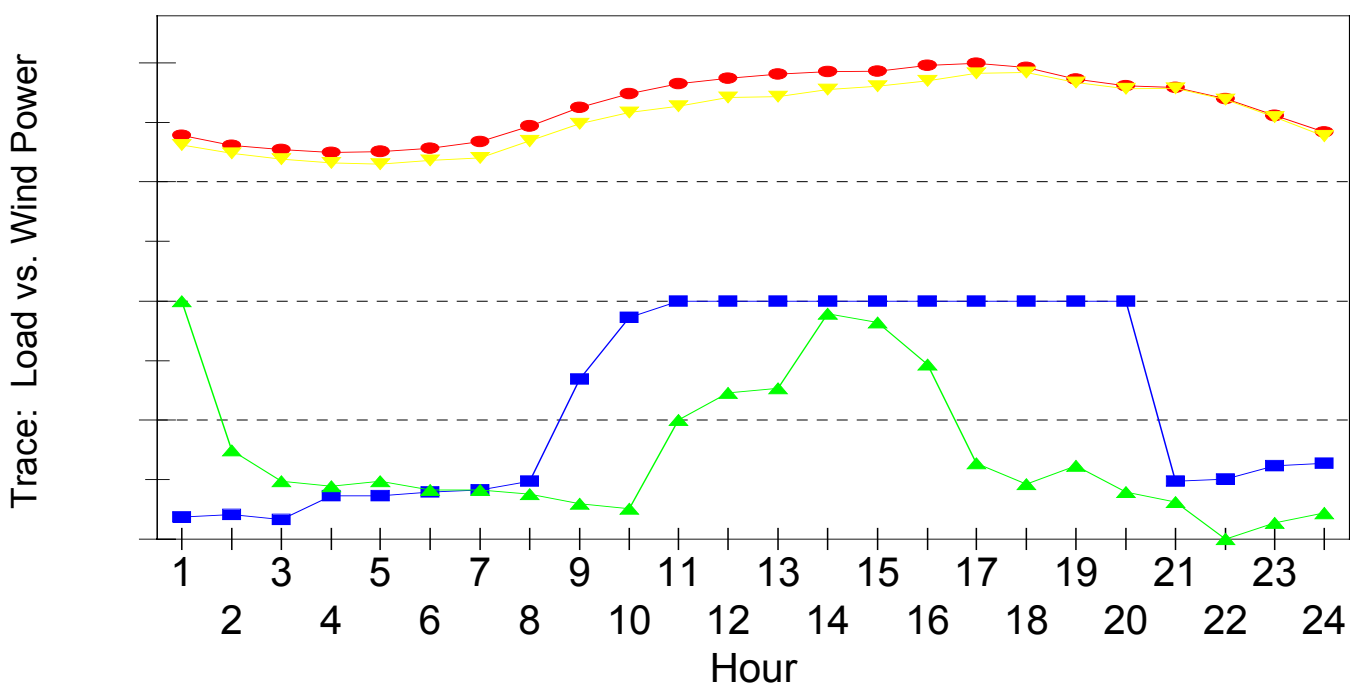

- Sat. Wind $\leadsto$ Sun. Wind — Sat. Load $\longrightarrow$ Sun. Load

Figure 22. Tace of weekend load, U1, HP wind 
The relevant marginal cost offset by wind is difficult to define and measure. We calculated the marginal costs by running a production cost model with and without wind and treating the difference as the benefit. However, these results are also sensitive to the number of plant shutdowns made possible by the wind resource and the allocation of avoided startup costs. This is one reason that the wind benefit is sensitive to the load level. At high-load levels, introducing a wind plant into the generation mix may cause highcost units to be curtailed and lower-cost units to be run at a reduced output level. A further increase in the wind resource, or reduction in load, may make decommitment possible for slow-start units. At this point the modeling techniques become important because the difference in commitment and decommitment algorithms causes alternative units to run in the simulations. To the extent that start-up costs are significant and included in the simulation, the marginal cost curve can contain points of discontinuity. This can happen if startup costs are included in the definition of marginal cost used by the model/utility/planner. Marnay and Strauss ${ }^{17}$, for example, list 12 variations of plausible marginal cost definitions. Although we ignore the extension of this problem to the long-term, in which the resource mix can change, Baumol ${ }^{18}$ and $\mathrm{Kahn}^{19}$ provide relevant discussions. Production-cost models calculate the expected plant output after accounting for various outage rates. The result will almost always be different than the actual generation schedule, in which units are actually out of service and have an actual output of zero. The expected marginal cost calculated by the model is, of course, based on the expected plant outputs. Therefore, actual marginal cost will vary according to which plants are out of service.

In reviewing the Elfin weekend results, it is important to distinguish Elfin's time-step from the $\mathrm{P}+$ chronology. Elfin divides the weekend into two sub-periods: peak and off-peak. The commitment level is based on calculating the target during the peak period, then committing whatever slow-start units are needed. Because some of these units cannot be decommitted during the weekend, Elfin cannot adjust commitment during the nighttime off-peak period if there is significant wind power on the system. During the off-peak period, we have approximately $200 \mathrm{MW}$ average excess committed capacity over the no-wind case. As in the $\mathrm{P}+$ simulation, Elfin is able to shift some of the pump-storage charging as a result of the available wind power.

\section{Summary}

Chronological models clearly provide a greater degree of realism and are capable of providing a deeper understanding of the effects that large-scale wind generation has on the optimal generation mix. However, LDC models do an excellent job of estimating costs and reliability on a somewhat broader timescale. The chronological results discussed in this section can be interpreted as limiting cases because we were unable to provide the model with detailed ramp rates and other generator data that would have given more precise results. Commercially-available models, as represented by those used in this study, have some shortcomings when modeling wind generating systems. The primary weakness is the inability to model both the time-varying wind profiles along with a probabilistic assessment of wind power availability. Improving either type of model is not difficult theoretically, because the overall approach is already built in to the models. The necessary computer resources to run either type of model are modest by today's standards. If a large number of scenarios are to be analyzed, or if the modeling period extends over a time horizon exceeding about 3 years, an LDC model would offer computational efficiency. Otherwise, the increased accuracy of a chronological model would generally be preferred.

Production-cost models should continue to be useful to owners of electric generation portfolios to develop optimal bids and bidding strategies. As the industry moves away from cost-markup pricing, generation owners will be motivated by profit, which still implies cost-minimization strategies. Although production-cost/reliability models will certainly undergo change to keep abreast of market and industry developments, the fundamental core problem of minimizing electricity cost will still be important. 


\section{Conclusions}

The conclusions we can draw from this work can be divided into two areas: modeling results and modeling methods.

\section{Modeling Results}

This paper describes modeling results for several utilities, wind sites, and wind turbines. In some cases, we used both an LDC model and a chronological model; in other cases, only an LDC model was applied. The first general observation is that in all cases modeled, wind power plants have economic value-both energy benefits and capacity benefits were found to be significant. Wind power plants are factored into the dispatch mix by a simple, rational strategy: if there is wind capacity on-line, it is used. Although it may seem as though the wind power plant is a baseload unit, it will not displace baseload generation. Instead, high-dispatch-cost units that are on the margin are the units that are displaced by wind power. The displacement of relatively high-cost units provides wind power plants with the capability of providing high-value displacement energy.

The energy value of wind power plants is highly dependent on the utility, wind turbine performance characteristics, and wind site. Because the wind power displaces power generated by marginal units, the value of power displaced will vary throughout the day. The marginal generator during low-load periods typically has a lower fuel cost than a marginal unit during the system peak. Therefore, the timing of the wind power has an important influence on the value of energy that is displaced. Wind sites that are highly correlated with load will have a higher energy displacement value because higher-cost energy is displaced during the peak period.

The value of wind power plants is sensitive to the load-level. This sensitivity is caused by the relatively higher-cost of supplying high loads, as compared to the lower cost of supplying low loads. Lower load levels can be met with a lower-cost generation mix, because the optimal generator choice is always the least-cost combination of generators (subject to various reliability and related constraints). As load increases, there is a need to use additional generators for which cost exceeds those already on-line. For a utility in a regulated environment, this implies that inaccurate load forecasts can have a dramatic effect on whether a wind power plant is judged to be an economic choice. In a restructured market, generating companies can obtain more value from wind power plants as they bid larger supplies into the pool. Bidding a wind plant into the day-ahead pool requires some knowledge about wind forecasts, a topic that is addressed in Part 2 of this paper.

Although controversial, the emission benefits provided by wind power are significant. In my judgement, a best effort should be made to quantify the value of foregone emissions that results from the use of wind power plants. Disagreement about the precise value of avoided emission is not a sound reason to set this value to zero. Instead, a range of values could be easily specified with the many production-cost models that allow for emissions valuation. The real issue is not whether avoided emissions have value, but rather how best to incorporate this important externality into rational decision-making.

\section{Modeling Methods}

It is apparent that chronological models provide a more detailed, accurate look at generation costs than do LDC models. Having said that, LDC models, as represented by Elfin, remain very powerful tools. Elfin provides several ways to model wind power plants. Modeling the wind plant as a load modifier has the 
advantage of retaining the hourly relationship between wind power and electric load. However, this approach does not allow for the probability of lack of wind power that results from lulls in the wind. The result is that the reliability measure for the system is overstated. Conversely, the wind plant can be modeled as a multi-block thermal unit with outage rates corresponding to different levels of wind output. This method has the advantage of correcting the reliability measure, but smoothes the wind power output unrealistically. This smoothing may artificially reduce the number of times that relatively higher-cost conventional generators are called upon during times of low wind power output. Depending on the relative costs of running conventional generators, this may not accurately represent a realistic benefit of the wind power plant. A technique that corrects these deficiencies is the Sequential Monte Carlo method, which is discussed in Part 2.

Overall cost estimates between $\mathrm{P}+$ and Elfin were very close. It is likely that data quality and availability, along with other modeling assumptions, play as important roles in accurate modeling as the style of the model. LDC models are not capable of performing daily analyses, which are important as we move from planning issues to operational issues. This makes the chronological model more attractive when general probabilistic results are not sufficient.

Another issue that affects accuracy is whether the model uses a piecewise representation of the load curve or a cumulant method. This poses a trade-off between accuracy and execution speed. Accuracy losses are more apparent with systems that have a high reliability because it is more difficult to represent the tail of the probability distribution as the probability of loss-of-load becomes very small. Cost differences that arise because of the load curve representation are not likely to be significant. Reliability estimates can differ significantly because of the relatively larger inaccuracies that can occur at the tail of the outage distribution.

Commitment and economic dispatch can be modeled more accurately in a chronological framework. Elfin is unable to decommit units for fractions of the week. P+ can decommit units on a dynamic basis, which is similar to operational practice. 


\section{References}

1. Hogan, W. Panel Session: "Electricity Restructuring," at the United States Association for Energy Economics Annual Conference. August 30, 1999. Orlando, FL.

2. Marnay, C.; Sezgen, O.; Bretz, S.; Markel, R.; Wiser, R. "Opportunities for Wind Resources in the Future Competitive California Power Market." Proceedings of the 21st Annual International Conference of the International Association for Energy Economics; Quebec, Canada. Cleveland, OH, USA: International Association for Energy Economics. pp. 303-312, (1998).

3. Kahn, E. "Numerical Techniques for Analyzing Market Power in Electricity." The Electricity Journal. July, 1998. Elsevier Science. pp. 34-43 (1998).

4. Surratt, W. "The Analytical Approach to Measuring Horizontal Market Power in Electric Utility Markets: A Historical Perspective," The Electricity Journal. Elsevier Science (1998).

5. Berry, C.; Hobbs, B.; Meroney, W.; O’Neill, R.; Stewart, Jr., W. “Analyzing Strategic Bidding Behavior in Transmission Networks." Presented at the IEEE Summer Power Meeting. San Diego, CA. July 13-16, 1998.

6. Milligan, M. Alternative Wind Power Modeling Methods Using Chronological and Load Duration Curve Production Cost Models. NREL/TP-441-8171. Golden, Colorado: National Renewable Energy Laboratory (1996).

7. Milligan, M.; Miller, A.; Chapman, F. "Estimating the Economic Value of Wind Forecasting to Utilities." Windpower '95 Proceedings; March 27-31, 1995; Washington, DC: American Wind Energy Association. NREL TP 441-7803. National Renewable Energy Laboratory, Golden, CO. (1995).

8. Silberberg, Eugene. The Structure of Economics: A Mathematical Analysis. McGraw Hill, New York, 1978.

9. Grubb, M, "Value of Variable Sources on Power Systems." IEEE Proceedings-C, Vol 138, No. 2. March 1991.

10. Milligan, M.R; Miller, A.H. "The Value of Windpower: An Investigation Using a Qualified Production Cost Model." Windpower '93 Proceedings; July 12-16, 1993; San Francisco, California. Washington, DC. American Wind Energy Association; pp. 74-81 (1993).

11. Elfin Algorithms Guide. Environmental Defense Fund. Oakland, CA., 1997.

12. Sandusky, W., et. al., Candidate Wind Turbine Generator Site Cumulative Meteorological Data Summary and Data for January 1982 Through September 1982. Pacific Northwest Laboratory, Richland, Washington. PNL-4663, 1983.

13. Milligan, M. Alternative Wind Power Modeling Methods Using Chronological and Load Duration Curve Production Cost Models. NREL/TP-441-8171. Golden, Colorado: National Renewable Energy Laboratory (1996). 
14. Rau, N.; Toy, P.; Schenk, K. "Expected Energy Production Costs by the Method of Moments." IEEE Transactions on Power Apparatus and Systems. Vol. PAS-99, No. 5 (1980).

15. Marnay, C.; Strauss, T. Chronological Model Comparison. California Public Utility Commission. Sacramento, CA., 1989.

16. Clarke, John M. Studies in the Economics of Overhead Costs. University of Chicago Press. Chicago, IL., 1923.

17. Milligan, M. Alternative Wind Power Modeling Methods Using Chronological and Load Duration Curve Production Cost Models. NREL/TP-441-8171. Golden, Colorado: National Renewable Energy Laboratory (1996).

18. Baumol, W. Economic Theory and Operations Analysis. Prentice Hall: Englewood Cliffs, New Jersey, 1979.

19. Kahn, E. Electric Utility Planning \& Regulation. The American Council for an Energy-efficient Economy, Washington, DC, 1991. 


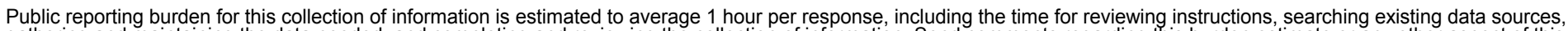

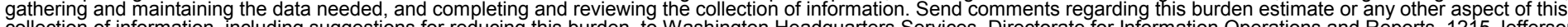

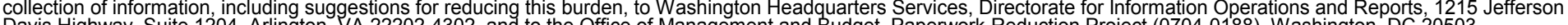
Davis Highway, Suite 1204, Arlington, VA 22202-4302, and to the Office of Management and Budget, Paperwork Reduction Project (0704-0188), Washington, DC 20503.
1. AGENCY USE ONLY (Leave blank)
2. REPORT DATE June 2000
3. REPORT TYPE AND DATES COVERED Technical Report

4. TITLE AND SUBTITLE

Modeling Utility-Scale Wind Power Plants Part 1: Economics

6. AUTHOR(S)

Michael R. Milligan

7. PERFORMING ORGANIZATION NAME(S) AND ADDRESS(ES)

National Renewable Energy Laboratory REPORT NUMBER

1617 Cole Blvd.

Golden, CO 80401-3393

NREL/TP-500-27514

9. SPONSORING/MONITORING AGENCY NAME(S) AND ADDRESS(ES)

National Renewable Energy Laboratory

10. SPONSORING/MONITORING

1617 Cole Blvd.

Golden, CO 80401-3393

11. SUPPLEMENTARY NOTES

NREL Technical Monitor:

12a. DISTRIBUTION/AVAILABILITY STATEMENT

National Technical Information Service

U.S. Department of Commerce

5285 Port Royal Road

Springfield, VA 22161

13. ABSTRACT (Maximum 200 words) As the worldwide use of wind turbine generators continues to increase in utility-scale applications, it will become increasingly important to assess the economic and reliability impact of these intermittent resources. Although the utility industry in the United States appears to be moving towards a restructured environment, basic economic and reliability issues will continue to be relevant to companies involved with electricity generation. This paper is the first of two that address modeling approaches and results obtained in several case studies and research projects at the National Renewable Energy Laboratory (NREL). This first paper addresses the basic economic issues associated with electricity production from several generators that include large-scale wind power plants. An important part of this discussion is the role of unit commitment and economic dispatch in production-cost models. This paper includes overviews and comparisons of the prevalent production-cost modeling methods, including several case studies applied to a variety of electric utilities. The second paper discusses various methods of assessing capacity credit and results from several reliability-based studies performed at NREL.

14. SUBJECT TERMS
wind energy, electricity generation

